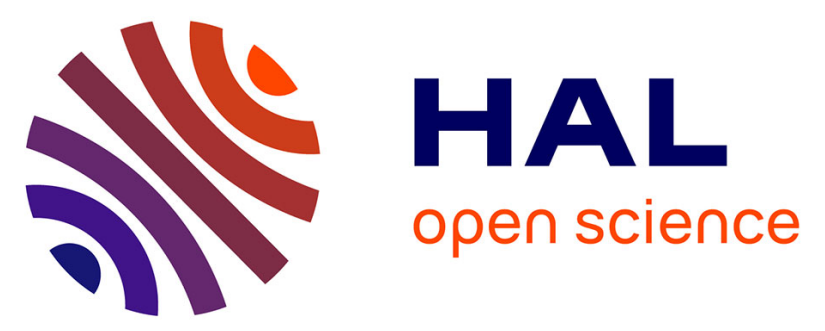

\title{
Experiments and modelling of a draft tube airlift reactor operated at high gas throughputs
}

Damien Colombet, Arnaud Cockx, Pascal Guiraud, Dominique Legendre

\section{To cite this version:}

Damien Colombet, Arnaud Cockx, Pascal Guiraud, Dominique Legendre. Experiments and modelling of a draft tube airlift reactor operated at high gas throughputs. Chemical Engineering Science, 2013, 104, pp.32-43. 10.1016/j.ces.2013.08.044 . hal-00919671

\section{HAL Id: hal-00919671 \\ https://hal.science/hal-00919671}

Submitted on 17 Dec 2013

HAL is a multi-disciplinary open access archive for the deposit and dissemination of scientific research documents, whether they are published or not. The documents may come from teaching and research institutions in France or abroad, or from public or private research centers.
L'archive ouverte pluridisciplinaire HAL, est destinée au dépôt et à la diffusion de documents scientifiques de niveau recherche, publiés ou non, émanant des établissements d'enseignement et de recherche français ou étrangers, des laboratoires publics ou privés. 


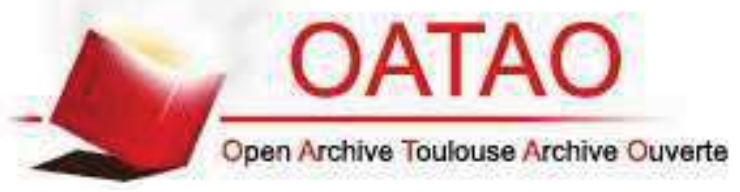

\section{Open Archive TOULOUSE Archive Ouverte (OATAO)}

OATAO is an open access repository that collects the work of Toulouse researchers and makes it freely available over the web where possible.

This is an author-deposited version published in : http://oatao.univ-toulouse.fr/ Eprints ID : 10536

To link to this article :

DOI:10.1016/j.ces.2013.08.044

URL : http://dx.doi.org/10.1016/j.ces.2013.08.044

\section{To cite this version :}

Colombet, Damien and Cockx, Arnaud and Guiraud, Pascal and Legendre, Dominique Experiments and modelling of a draft tube airlift reactor operated at high gas throughputs. (2013) Chemical Engineering Science, vol. 104 . pp. 32-43. ISSN 0009-2509

Any correspondance concerning this service should be sent to the repository administrator: staff-oatao@listes-diff.inp-toulouse.fr 


\title{
Experiments and modelling of a draft tube airlift reactor operated at high gas throughputs
}

\author{
D. Colombet ${ }^{\mathrm{a}, \mathrm{b}, \mathrm{c}, \mathrm{d}, \mathrm{e}, \mathrm{f}}$, A. Cockx ${ }^{\mathrm{a}, \mathrm{b}, \mathrm{c}, *}, \mathrm{P}$. Guiraud ${ }^{\mathrm{a}, \mathrm{b}, \mathrm{c}}$, D. Legendre $^{\mathrm{d}, \mathrm{e}}$ \\ a Université de Toulouse, INSA, UPS, INP, LISBP, 135 Avenue de Rangueil, F-31077 Toulouse, France \\ b INRA, UMRA792 Ingénierie des Systèmes Biologiques et des Procédés, F-31400 Toulouse, France \\ ${ }^{\mathrm{c}}$ CNRS, UMR5504, F-31400 Toulouse, France \\ ${ }^{\mathrm{d}}$ Université de Toulouse, INPT, UPS, IMFT (Institut de Mécanique des Fluides de Toulouse) Allée Camille Soula, F-31400 Toulouse, France \\ e CNRS, IMFT, F-31400 Toulouse, France \\ ${ }^{\mathrm{f}}$ Rhodia Opérations - Solvay, 85 Avenue des Frères Perret, BP 62, 69192 Saint Fons, France
}

\section{H I G H L I G H T S}

- Study and modelling of an annular sparged draft tube airlift at high gas throughputs.

- Strong influence of collective effects and flow pattern on the riser hydrodynamics.

- Weak effect of gas volume fraction increase on bubble's mass transfer coefficient.

- Volumetric mass transfer coefficient is proportional to the gas superficial velocity.

Keywords:

Bubble columns

Hydrodynamics

Mass transfer

Multiphase flow

Draft tube airlift

\begin{abstract}
A B S T R A C T
One-dimensional modelling of global hydrodynamics and mass transfer is developed for an annulus sparged draft tube airlift reactor operating at high gas throughputs. In a first part, a specific closure law for the mean slip velocity of bubbles in the riser is proposed according for, in one hand, the collective effects on bubble rise velocity and, in the other hand, the size of the liquid recirculation in the airlift riser. This global hydrodynamics model is found to well explain the global gas volume fraction measurements in the airlift riser for a wide range of superficial gas velocity $\left(0.6 \leq J_{G} \leq 10 \mathrm{~cm} \mathrm{~s}^{-1}\right)$. In a second part, mass transfer in the airlift has been studied by using the gassing-out method and a dual-tip optical probe to measure the bubble size distributions. As for bubble columns, in such airlift, the volumetric mass transfer coefficient appears to be quite proportional to the gas superficial velocity. Finally, as in Colombet et al. (2011), mass transfer at the bubble scale seems to be weakly influenced by an increase of gas volume fraction.
\end{abstract}

\section{Introduction}

Airlift reactors are widely used in many processes, like absorption or desorption operations for water treatment or chemical industry applications. At low gas volume fraction, the behavior of internal or external airlifts has been thoroughly studied and modeled (Bello, 1981; Jones, 1985; Wachi et al., 1991; Kushalkar and Pangarkar, 1994; Chisti et al., 1995; Cockx et al., 1997; Gourich et al., 2005; Talvy et al., 2005; Luo and Al-Dahhan, 2008). However at high gas volume fraction, the understanding and the modelling of global hydrodynamics and mass transfer stays clearly a challenge. In chemical industry, the use of high

\footnotetext{
* Corresponding author at: Université de Toulouse, INSA, UPS, INP, LISBP, 135 Avenue de Rangueil, F-31077 Toulouse, France. Tel.: + 33561559797.

E-mail address: arnaud.cockx@insa-toulouse.fr (A. Cockx).
}

gas volume fraction contactors is particularly interesting for mass transfer operations coupled with a chemical reaction in the liquid phase. Dense bubbly flows provide a mixing of reactants in the liquid phase and a high interfacial area that appears to be very useful when mass transfer limits the chemical reaction.

The difficulty increases also for complex geometries as it can be found in annulus sparged draft tube airlifts (Fig. 1a). Many studies have focused on draft tube airlifts with the gas injection located in the center of the reactor (Jones, 1985; Wachi et al., 1991; Merchuk et al., 1994; Kushalkar and Pangarkar, 1994; Pironti et al., 1995; Kojima et al., 1999; Reza Mehmia et al., 2005; Shariati et al., 2007; Luo and Al-Dahhan, 2008). But to our knowledge only a few works exist on draft tube airlift with the injection located in the annular volume (Botton et al., 1978, 1980; Chisti et al., 1995; Wongsuchoto and Pavasant, 2004; Zhang et al., 2010). With such gas injection, a large liquid recirculation is progressively formed in the airlift 
a

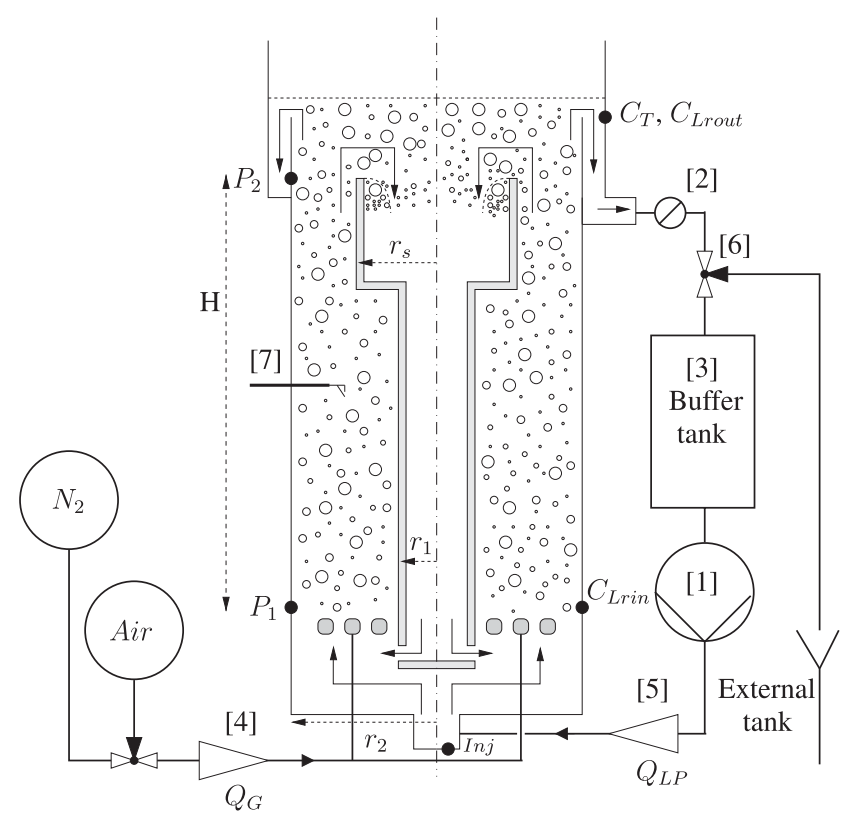

b

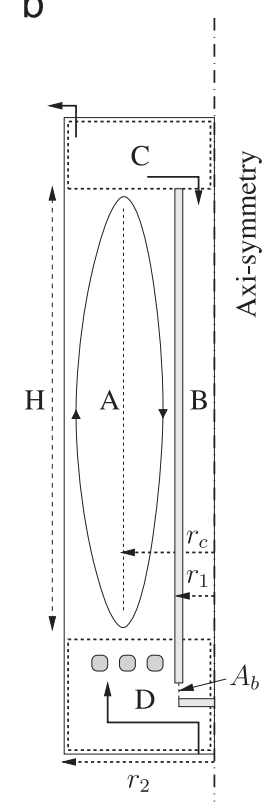

Fig. 1. (a) Pilot plant and (b) axisymmetric airlift representation.

riser (Wongsuchoto and Pavasant, 2004). This liquid recirculation is similar to those formed in conventional bubble columns if the gas injection is not uniformly distributed on the column cross section (Lockett and Kirkpatrick, 1975; Molerus and Kurtin, 1986; Becker et al., 1994; Vitankar and Joshi, 2002). Consequently, compared to standard airlift reactors, the study of annulus sparged airlift is made difficult because of the complexity of gas-liquid hydrodynamics in the riser, especially in the case of high gas throughputs.

The aim of this article is to contribute to global modelling of hydrodynamics and mass transfer process in an annulus sparged draft tube airlift reactors by means of experimental investigation as well as 1D modelling.

In a first step, experimental set-up and measurements techniques are described. Then, hydrodynamic experimental results are presented focusing on bubble size and gas volume fraction measurements. In a third step, a global hydrodynamic model is proposed to explain the evolution of the riser global gas volume fraction. In a last step, using the plug flow with axial dispersion model so-called Axial Dispersion Model (ADM), the liquid-side volumetric mass transfer coefficient $k_{\mathrm{L}} a_{I}$ is measured by adjusting the ADM prediction on experimental dissolved oxygen concentration time evolution. To perform mass transfer measurements, axial dispersion in the riser is also measured independently. Mass transfer experimental results are then analyzed considering recent works on mass transfer in bubbly flows.

\section{Experimental set-up}

\subsection{Reactor design and gas-liquid system}

The experimental installation is depicted in Fig. 1a. The whole installation includes an airlift reactor, a centrifugal pump ([1]) and a buffer tank ([3]) of volume $V_{\text {Tank }}\left(\approx 8 V_{\text {Airlift }}\right)$. The reactor is made of two vertical concentric tubes of radii $r_{1}$ and $r_{2}$. At the top of the draft tube, a separator of radius $r_{s}$ ensures bubbles disengagement. The gas phase is introduced through pierced toroidal gas spargers, at the riser bottom. Bubbles are formed in a jet regime. Gas and liquid inlet flow rates $\left(Q_{G}\right.$ and $\left.Q_{I P}\right)$ are monitored by flow controllers ([4-5]). The airlift volume is about $0.13 \mathrm{~m}^{3}$ and, as shown in Fig. $1 \mathrm{~b}$, its geometry can be divided in four main parts:

- a riser corresponding to the annular volume between the two concentric tubes $[A]$,

- a downcomer corresponding to the internal smallest inner tube volume $[B]$,

- an upper connecting domain $[C]$,

- a lower connecting domain $[D]$.

The pilot plant can run closed to the liquid $\left(Q_{L P}=0\right)$ or open to the liquid $\left(Q_{L P}>0\right)$. In that last case, a valve ([2]) in Fig. $\left.1 \mathrm{a}\right)$ is placed at the reactor liquid outlet to maintain the liquid level in the airlift.

In conventional airlift contactor, the downcomer can be aerated or not, depending on whether or not the liquid velocity is strong enough to entrain bubbles coming from the riser into the downcomer. At the top of the downcomer, if the liquid downward velocity $U_{L S}$ is lower than the single bubble relative velocity $V_{z}^{\infty}$, no bubble can be trapped in the downcomer. Otherwise, the downcomer is aerated. In our experimental plant, the gas-liquid separator was specially designed (by controlling the separator radius $r_{s}$ ) to avoid downcomer aeration whatever the gas throughput $\left(U_{L s}<V_{z}^{\infty}\right)$. Moreover, the clearance distance above the draft tube has been chosen to avoid strong curvature of the free surface (vortex formation). As a result, in the downcomer, gas and liquid volume fractions are respectively $R_{G d}=0$ and $R_{L d}=1$.

The gas-liquid system is composed of air and water with $0.1 \%$ of butanol $(\mathrm{v} / \mathrm{v})$ at ambient temperature and pressure. A small amount of butanol was added to tap water in order to increase easily gas volume fraction by decreasing the surface tension from $73 \mathrm{mN}$ down to $65 \mathrm{mN}$ (Habrdova et al., 2004). It results in smaller bubbles with slightly lower terminal rising velocities than in pure water (Camarasa et al., 1999; Veera et al., 2001). Meanwhile, the addition of alcohol in water is not considered as a contamination of the bubble surface, since it is known to decrease homogeneously the surface tension. The main fluid properties are summarized in Table 1. 
Table 1

Fluids properties at $T=20^{\circ} \mathrm{C}$ and $P=101325 \mathrm{~Pa}$.

\begin{tabular}{lll}
\hline$\rho_{L}$ & 998.2 & $\mathrm{~kg} \mathrm{~m}^{-3}$ \\
$\mu_{L}$ & $1.0 \times 10^{-3}$ & $\mathrm{~Pa} \mathrm{~s}$ \\
$\rho_{G}$ & 1.2 & $\mathrm{~kg} \mathrm{~m}^{-3}$ \\
$\sigma$ & $65 \times 10^{-3}$ & $\mathrm{~N} \mathrm{~m}^{-1}$ \\
$D_{L}$ & $2.6 \times 10^{-9}$ & $\mathrm{~m}^{2} \mathrm{~s}^{-1}$ \\
$\mathrm{He}_{\mathrm{O}_{2}}$ & $4.05 \times 10^{9}$ & $\mathrm{~Pa}$ \\
\hline
\end{tabular}

\subsection{Measurements techniques}

The measurement of the averaged gas volume fraction in the riser was performed from the vertical hydrostatic pressure difference as

$R_{G r}=1-\frac{P_{1}-P_{2}}{\rho_{L} g H}$

where $H$ is the riser height. The experimental set-up is equipped with a dual-tip optical probe ( $R B I$ Instrumentation) in the riser located at a radial position $r=\left(r_{2}+r_{1}\right) / 2$ and at the mid height of the reactor $h=H / 2$ ([7]). The optical probe used in this work is made of two glass fibers having a diameter of $50 \mu \mathrm{m}$ at the sensitive part. The smallest measurable bubble is of $0.1 \mathrm{~mm}$ in diameter. There is no upper limit for the size of bubbles that could be measured. The record duration of the probe signal have been adjusted so that the statistical convergence of measurements is ensured.

To characterize bubble sizes, the chord distributions have been treated to obtain bubble volume-equivalent diameter distributions. In a first step, as previously in Roig and Larue de Tournemine (2007), assuming that size and velocity distributions are uncorrelated, the detected bubble size distribution is obtained by the method described in the work of Clark and Turton (1988), by using a matrix inversion. In a second step, the correction proposed by Herringe and Davis (1976) is applied to take into account the variation of the volume scanned by the probe with the bubble size. The detected bubble size distribution is thus corrected by the inverse of bubbles square radius. Indeed those results will be interpreted with care since it does not correspond to a direct measurement of bubble size distributions. However, as a matter of fact, optical probes are currently the only device that enable statistically converged bubble size distribution measurements in dense bubbly flows up to $30 \%$. For more detailed on optical probe signal treatment in non uniform two-phase flows, one can refer to Cartellier (1999).

The increase in gas volume fraction leads to a decrease in both relative velocities (Wallis, 1969; Zenit et al., 2001; Garnier et al., 2002; Riboux et al., 2010; Roghair et al., 2011; Colombet et al., 2011) and bubble Weber numbers $W e=\rho_{L} V_{z}^{2} d_{10} / \sigma$. As a result, a bubble in a swarm tends to be more spherical than a single bubble of same equivalent diameter. Consequently the demodulation of chord distributions is performed here by assuming that bubbles are spherical $(\chi=1)$. Mean equivalent diameter $d_{10}$ and Sauter mean diameter $d_{32}$ can then be calculated.

The measurements of gas volume fraction and Sauter mean diameter make possible the estimation of the interfacial area per volume unit $a_{I}$ in the riser that is required to study thoroughly mass transfer.

The axial dispersion in the liquid was measured by generating a set of Residence Time Distributions (RTD) at various gas flow rates. For that purpose, first, the liquid flow at the outlet was sent directly to an external tank, bypassing the buffer tank by means of a valve [6]. Next, a tracer $\left(\mathrm{NaCl} / \mathrm{H}_{2} \mathrm{O}\right)$ was suddenly injected as a Dirac pulse at the bottom position indicated by Inj in Fig. 1a. Meanwhile, the analysis of the time evolution of the tracer concentration $C_{T}$ at the airlift outlet was acquired by conductivity measurements with a liquid sampling method. Finally, RTD measurements provided the axial dispersion coefficient in the liquid phase $E_{Z L r}$ along the riser.

In order to perform mass transfer experiments, the classical gassing-out method is employed for various gas flow rates. Gaseous nitrogen was first injected through spargers to remove oxygen from the liquid. After a sufficiently long time, the oxygen concentration within the liquid vanishes. The gas inlet was then switched from nitrogen to air with an oxygen mass concentration of $C_{G 0}=272 \mathrm{mg} \mathrm{L}^{-1}$. During this second step, in order to estimate the global mass transfer coefficient $\left(k_{L} a_{I}\right)$, oxygen concentrations at the top $\left(C_{\text {Lrout }}\right)$ and at the bottom $\left(C_{\text {Lrin }}\right)$ of the riser were recorded by two dissolved oxygen probes (MDO2 Neosens).

\subsection{Operating conditions}

The reactor hydrodynamics is studied for two liquid superficial velocities $J_{L P}=0$ and $J_{L P}=6.5 \mathrm{~cm} \mathrm{~s}^{-1}$, with a gas superficial velocity range of $0.6 \leq J_{G} \leq 10 \mathrm{~cm} \mathrm{~s}^{-1}$ and with a pretty large gas volume fraction range of $5 \leq R_{G r} \leq 39 \%$. Mass transfer experiments are carried out with a liquid flowrate corresponding to a superficial velocity of $J_{L P}=6.5 \mathrm{~cm} \mathrm{~s}^{-1}$ and with a gas volume fraction range of $9.6 \leq R_{G r} \leq 29 \%$.

\section{Bubble volume fraction and size distributions}

In this section, the bubbles size distributions and gas volume fraction measurements are presented.

\subsection{Bubble size distributions}

A typical chord length distribution from the dual-tip optical probe is displayed in Fig. 2 for $J_{L P}=6.5 \mathrm{~cm} \mathrm{~s}^{-1}$ and $J_{G}=1.3 \mathrm{~cm} \mathrm{~s}^{-1}$. Equivalent diameter distributions are obtained from chord length demodulation considering the correction of Herringe and Davis (1976) to take into account measurement volume variation with the bubble size. These equivalent diameter distributions for $J_{L P}=0$ and $J_{L P}=6.5 \mathrm{~cm} \mathrm{~s}^{-1}$ are respectively depicted in Fig. 3a and b. As reported in Table 2, the range of the corresponding mean equivalent diameters is $2 \leq d_{10} \leq 3 \mathrm{~mm}$.

The analysis of the dual-tip optical probe data reveals also that the presence of a liquid flow rate in the riser modifies the equivalent diameter distributions. As shown, in Fig. 3a, without inlet liquid flow rate $\left(J_{L P}=0\right)$, when the gas flow rate $Q_{G}$ increases, size distributions are slightly more spread out. Whereas, with a liquid flow rate, as shown in Fig. 3b, equivalent diameter distributions are nearly not

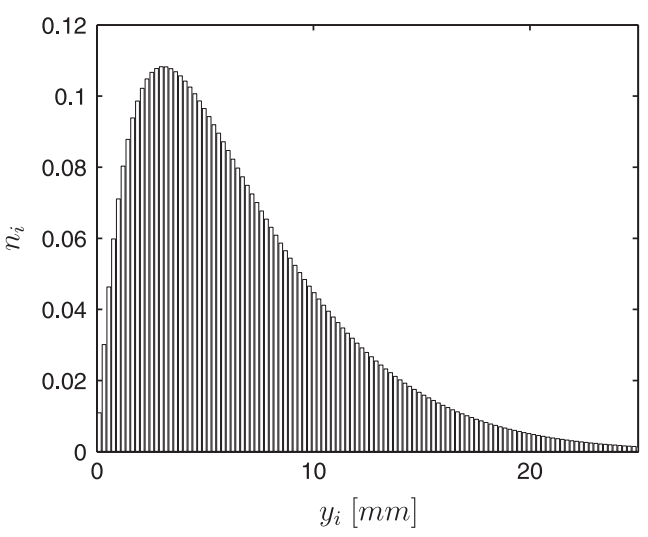

Fig. 2. Typical chord length distribution from the dual-tip optical probe for $J_{L P}=6.5 \mathrm{~cm} \mathrm{~s}^{-1}$ and $J_{G}=1.3 \mathrm{~cm} \mathrm{~s}^{-1}$. 
affected by an increase in the gas flow rate. As reported in Table 2, for $J_{L P}=6.5 \mathrm{~cm} \mathrm{~s}^{-1}$, this behavior results in quasi constant average equivalent diameters $\left(d_{10} \approx 2 \mathrm{~mm}\right)$ and Sauter mean diameters $\left(d_{32} \approx 7 \mathrm{~mm}\right.$ ), for the different gas flow rates. Thus, the presence of the liquid superficial velocity seems to stabilize the bubble size distribution. One explanation could be that the local liquid velocity at the spargers is so strong that it controls bubbles formation mechanism.

The size distribution is characterized by a high standard deviation of about $\sigma\left(d_{e q}\right) \approx 2.2 \mathrm{~mm}$ corresponding to approximately $100 \%$ of the

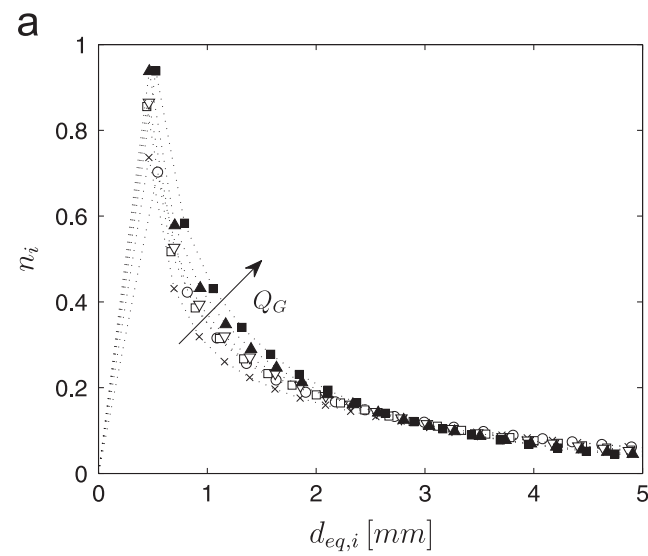

b

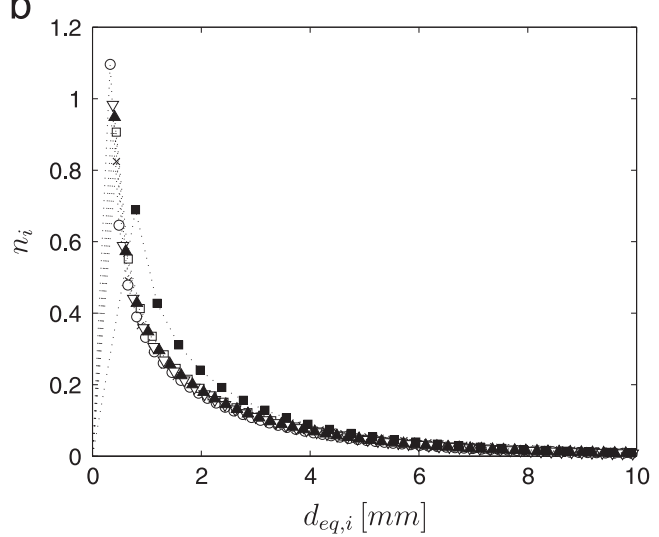

Fig. 3. Volume-equivalent diameter distributions estimated from chord length distributions: (a) without inlet liquid flow rate $J_{L P}=0$ ) and (b) with a liquid flow rate $\left(J_{L P}=6.5 \mathrm{~cm} \mathrm{~s}^{-1}\right)$ for $J_{G}=\times 1.3, \circ 2.0, \square 3.3, \nabla 4.4, \triangle 5.5,-6.6 \mathrm{~cm} \mathrm{~s}^{-1}$. mean equivalent diameter (i.e. $\sigma\left(d_{\text {eq }}\right) / d_{10} \approx 100 \%$ ). The bubble size distribution is strongly polydispersed and, as a result, the characteristic diameters of the bubble population are quite different. For $J_{L P}=6.5 \mathrm{~cm} \mathrm{~s}^{-1}$, the Sauter mean diameter $d_{32}$ is found to be more than 3 times higher than the mean diameter $d_{10}$. The polydispersity of the bubble population has been also qualitatively confirmed by different photographs made above the gas injection point.

\subsection{Gas volume fraction}

In Fig. 4, the riser gas volume fraction is reported versus the gas superficial velocity for the two different liquid inlet flow rates $J_{L P}=0(\square)$ and $J_{L P}=6.5 \mathrm{~cm} \mathrm{~s}^{-1}(\circ)$. As usual, for a given liquid inlet flow rate, the global gas volume fraction $R_{G r}$ increases with the gas flow rate. Moreover, when the liquid flow rate $J_{L r}$ increases in the riser at a given gas flow rate, the experimental results show a decrease of the average gas volume fraction.

These two behaviors can be easily explained at first order by considering the classical slip velocity model. As recalled by Cockx et al. (1997) considering $G$ the slip velocity between gas and liquid phases, one can show that the gas volume fraction of a bubbly flow in a vertical channel can be estimated as follows:

$R_{G r}=\frac{\left(J_{G}+J_{L r}+G\right)-\sqrt{\left(J_{G}+J_{L r}+G\right)^{2}-4 G J_{G}}}{2 G}$

where $G$ corresponds to the mean relative velocity between bubbles and the liquid in a cross section. As a consequence, for given gas superficial velocity $J_{G}$ and slip velocity, the derivative of

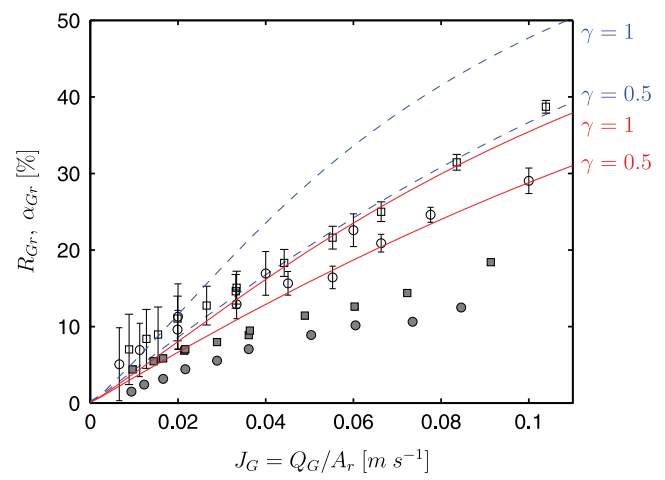

Fig. 4. (Color online) Global $\left(R_{G r}\right)$ and local $\left(\alpha_{G r}\right)$ gas volume fraction in the riser versus $J_{G}$; Exp. data: $R_{G r}$ for $\square J_{L P}=0$ and for $\circ J_{L P}=6.5 \mathrm{~cm} \mathrm{~s}^{-1}, \alpha_{G r}$ for $J_{L P}=0$ and for $\bullet J_{L P}=6.5 \mathrm{~cm} \mathrm{~s}^{-1}$; - model results for $J_{L P}=0$; - model results for $J_{L P}=6.5 \mathrm{~cm} \mathrm{~s}^{-1}$.

Table 2

Hydrodynamic results.

\begin{tabular}{|c|c|c|c|c|c|c|c|c|c|c|c|}
\hline \multirow{2}{*}{$\begin{array}{l}J_{G} \\
\mathrm{~cm} \mathrm{~s}^{-1}\end{array}$} & \multicolumn{4}{|c|}{ Exp. data } & \multicolumn{7}{|c|}{ Model results } \\
\hline & $R_{G r}(\%)$ & $\begin{array}{l}d_{10} \\
\mathrm{~mm}\end{array}$ & $\begin{array}{l}d_{32} \\
\mathrm{~mm}\end{array}$ & $\begin{array}{l}\sigma\left(d_{10}\right) \\
\mathrm{mm}\end{array}$ & $R_{G r}(\%)$ & $\begin{array}{l}\gamma \\
-\end{array}$ & $\begin{array}{l}U_{L r} \\
\mathrm{~m} \mathrm{~s}^{-1}\end{array}$ & $\begin{array}{l}U_{G r} \\
\mathrm{~m} \mathrm{~s}^{-1}\end{array}$ & $\begin{array}{l}U_{L d} \\
\mathrm{~m} \mathrm{~s}^{-1}\end{array}$ & $\begin{array}{l}U_{L s} \\
\mathrm{~m} \mathrm{~s}^{-1}\end{array}$ & $\begin{array}{l}Q_{L d} / Q_{L r} \\
-\end{array}$ \\
\hline \multicolumn{12}{|c|}{ for $J_{L P}=0 \mathrm{~cm} \mathrm{~s}^{-1}$} \\
\hline 1.3 & 8.4 & 3.0 & 8.4 & 3.8 & 7.2 & 1 & 0.03 & 0.18 & 0.35 & 0.06 & 1 \\
\hline 2.0 & 11.0 & 2.9 & 8.2 & 3.4 & 11.5 & 1 & 0.05 & 0.17 & 0.44 & 0.08 & 1 \\
\hline 4.4 & 18.3 & 2.4 & 7.1 & 2.5 & 18.3 & 0.5 & 0.06 & 0.24 & 0.56 & 0.09 & 1 \\
\hline 6.6 & 25.0 & 2.0 & 5.8 & 1.9 & 25.3 & 0.5 & 0.08 & 0.25 & 0.67 & 0.11 & 1 \\
\hline 10.4 & 38.7 & 2.4 & 6.4 & 2.2 & 37.7 & 0.5 & 0.12 & 0.28 & 0.80 & 0.14 & 1 \\
\hline \multicolumn{12}{|c|}{ for $J_{L P}=6.5 \mathrm{~cm} \mathrm{~s}^{-1}$} \\
\hline 2.2 & 9.6 & 2.1 & 7.0 & 2.3 & 8.7 & 1 & 0.11 & 0.25 & 0.38 & 0.06 & 0.34 \\
\hline 4.3 & 16.7 & 2.2 & 7.0 & 2.3 & 17.4 & 1 & 0.14 & 0.25 & 0.54 & 0.09 & 0.43 \\
\hline 6.5 & 20.8 & 2.6 & 6.8 & 2.2 & 20.0 & 0.5 & 0.15 & 0.32 & 0.58 & 0.10 & 0.44 \\
\hline 10.8 & 29.0 & - & - & - & 30.6 & 0.5 & 0.19 & 0.35 & 0.72 & 0.12 & 0.50 \\
\hline
\end{tabular}


Eq. (2) shows that an increase of $J_{L r}$ results basically in a decrease of $R_{G r}$. When the reactor is closed to the liquid $J_{L r}$ increases under the airlift effect while increasing the gas flow rate. If the reactor is open to the liquid, the additional liquid flow through the riser $\left(Q_{L P}\right)$ accentuates the increase of $J_{L r}$, resulting in lower gas volume fraction.

In Fig. 4, the local riser volume fraction $\alpha_{G r}$ measured at the mid riser height has been also reported for $J_{L P}=0(\square)$ and for $J_{L P}=6.5 \mathrm{~cm} \mathrm{~s}^{-1}(\bullet)$. It can be first noticed that, $\alpha_{G r}$ changes in the same way than $R_{G r}$ when increasing $J_{G}$ and/or $J_{L P}$. However, the local gas volume fraction $\alpha_{G r}$ remains always lower than the global one $R_{G r}$. This suggests significant spatial inhomogeneity of the local gas volume fraction $\left(\alpha_{G r}\right)$ resulting in pressure gradients that can make possible the formation of a liquid loop in the riser (Fig. 1b). On the basis of these experimental observations about the bubbly flow in the airlift, a 1D model for the prediction of $R_{G r}$ versus $J_{G}$ is proposed in the following section. This 1D model is then extended to mass transfer.

\section{Hydrodynamic 1D model}

In this section, a one dimensional modeling approach of the airlift hydrodynamics is proposed. First, we present the global steady state model for a fully developed gas-liquid flow. Then, a specific model is introduced for the riser. Finally, the whole global airlift model for the reactor is presented and compared to global gas volume fraction measurements.

\subsection{D modelling of gas-liquid fully developed flow at steady state}

Under steady state conditions, the cross-section integration of the Euler-Euler incompressible two fluid flow equations (mass and momentum conservation) gives the following one dimensional model for gas $(k=G)$ and liquid $(k=L)$ phases (Talvy et al., 2005):

$R_{k} U_{k}=\frac{Q_{k}}{A}$

$R_{k} \frac{\partial}{\partial z} P=\frac{L_{k}^{w}}{A} \tau_{k}^{w}+a_{p}^{I} \tau_{k}^{I}-R_{k} \rho_{k} g$,

with the constitutive relation: $R_{L}+R_{G}=1$, where $R_{G}$ and $R_{L}$ are respectively the spatial average of gas and liquid volume fractions on the cross-section area of the flow. $U_{k}$ stands for the spatial volume-fraction-weighted average velocity of phase $k . P$ is the spatial average pressure on the cross-section area of the flow considering the equality between gas and liquid pressures (i.e. neglecting Laplace pressure). $L_{k}^{w}$ is the perimeter of the wall wet by phase $k . \tau_{k}^{w}$ stands for the wall shear stress exerted by phase $k . a_{p}^{I}$ is the projected interfacial area per unit of volume and $\tau_{k}^{I}$ is the interfacial stress defined so that $\tau_{G}^{I}=-\tau_{L}^{I}=\tau^{I}$. This stress results from local pressure and viscous stress distributions along the bubble interface.

Instead of solving directly Eq. (4) with $k=G$ and $k=L$, one generally prefers to consider an explicit relation for the average gas velocity $U_{G}$ and the sum of the momentum conservation equations (Eq. (4)), that can be simplified as follows, considering $\rho_{G} / \rho_{L} \ll 1$ and $\tau_{G}^{w} \ll \tau_{L}^{w}$

$\frac{\partial}{\partial z} P=\frac{L_{L}^{w}}{A} \tau_{L}^{w}-R_{L} \rho_{L} g$,

where the wall shear stress $\tau_{L}^{w}=(1 / 2) \rho_{L} f_{w} U_{L}^{2}$ is modeled using the relations proposed by Colin et al. (1996) for the shear coefficient $f_{w}$. Finally, to describe the average gas velocity $U_{G}$, a slip velocity
Table 3

Complete airlift global hydrodynamics model.

\begin{tabular}{ll}
\hline Riser & Non aerated downcomer $\left(U_{L s}<V_{z}^{\infty}\right)$ \\
$R_{G r} U_{G r}=Q_{G r} / A_{r}$ & $R_{G d}=0$ \\
$R_{L r} U_{L r}=Q_{L r} / A_{r}$ & $R_{L d}=1$ \\
$1=R_{G r}+R_{L r}$ & $U_{L d}=Q_{L d} / A_{d}$ \\
$U_{G r}=U_{L r}+G_{r}$ & \\
Flow rates balance & \\
$Q_{L r}=Q_{L d}+Q_{L P}$ & \\
$Q_{G r}=Q_{G}$ & \\
Momentum balance & \\
$\left(R_{L d}-R_{L r}\right) \rho_{L} g H=\frac{1}{2} \rho_{L}\left[\left(\left(L_{L d}^{w} H / A_{d}\right) f_{d}^{w}+K_{\text {inf }}\right) U_{L d}^{2}+\left(\left(L_{L r}^{w} H / A_{r}\right) f_{r}^{w}\right) U_{L r}^{2}\right]$ \\
\hline
\end{tabular}

model can be used as

$U_{G}=U_{L}+G$

If a closure relation is given for $G$, unknown variables $\left(U_{L}, U_{G}, R_{L}\right.$, $R_{G}, P$ ) can thus be obtained by solving a set of 5 equations (Eq. (3) for $k=G$ and $k=L$, Eq. (5), Eq. (6) and $R_{L}+R_{G}=1$ ).

\subsection{Airlift global momentum balance}

The integration of the momentum balance (Eq. (5)) along the riser $(r)$ and along the downcomer $(d)$ can be simplified as

$$
\begin{aligned}
& \Delta P_{r} \approx-R_{L r} \rho_{L} g H-\frac{1}{2} \rho_{L} \frac{L_{L r}^{w} H}{A_{r}} f_{r}^{w} U_{L r}^{2} \\
& \Delta P_{d} \approx-R_{L d} \rho_{L} g H+\frac{1}{2} \rho_{L} \frac{L_{L d}^{w} H}{A_{d}} f_{d}^{w} U_{L d}^{2},
\end{aligned}
$$

with $H$ the airlift height. Then, neglecting the pressure drop in the upper connecting domain $\Delta P_{\text {sup }}$ compared to the one in the lower connecting domain $\Delta P_{\text {inf }}=(1 / 2) \rho_{L} K_{\text {inf }} U_{L d}^{2}$ (Chisti and Moo-Young, 1993), using Eqs. (7) and (8) the momentum balance on the entire loop of the airlift: $\Delta P_{r}-\Delta P_{d}=\Delta P_{\text {sup }}+\Delta P_{\text {inf }}$, can be written as follows:

$\left(R_{L d}-R_{L r}\right) \rho_{L} g H=\frac{1}{2} \rho_{L}\left[\left(\frac{L_{L d}^{w} H_{1}}{A_{d}} f_{d}^{w}+K_{i n f}\right) U_{L d}^{2}+\left(\frac{L_{L r}^{w} H_{r}}{A_{r}} f_{r}^{w}\right) U_{L r}^{2}\right]$,

where the singular pressure drop coefficient is estimated as $K_{\text {inf }}=11.402\left(A_{d} / A_{b}\right)^{0.789}$ (Chisti, 1989), with $A_{b}$ the surface area at the downcomer bottom (see Fig. 1b).

\subsection{Global airlift hydrodynamic model}

Considering Eqs. (3), (5), (6) and the momentum balance, the resulting complete global model for the airlift hydrodynamics is summarized in Table 3. This model can be rewritten in a simpler system, where $Q_{L r}, Q_{I d}$ and $R_{G r}$ satisfy the following three equations:

$Q_{L r}=Q_{L d}+Q_{L P}$

$\frac{Q_{G}}{A_{r} R_{G r}}=\frac{Q_{L r}}{A_{r}\left(1-R_{G r}\right)}+G_{r}$

$2 R_{G r} H g=\left(K_{d}+K_{i n f}\right)\left(\frac{Q_{L d}}{A_{d}}\right)^{2}+K_{r}\left(\frac{Q_{L r}}{A_{r}\left(1-R_{G r}\right)}\right)^{2}$,

with the riser slip velocity between gas and liquid phases $G_{r}=$ $U_{G r}-U_{L r}, \quad U_{L r}=Q_{L r} /\left(A_{r}\left(1-R_{G r}\right)\right), \quad U_{G r}=Q_{G} /\left(A_{r} R_{G r}\right), \quad U_{L d}=Q_{L d} / A_{d}$, $K_{r}=L_{L r}^{w} H f_{r}^{w} / A_{r}, K_{d}=L_{L d}^{w} H f_{d}^{w} / A_{d}$. The system is solved by using Matlab $^{\circledR}$.

A more detailed analysis of the results obtained with the model for our experimental conditions reveals that the pressure loss due to the wall friction of the liquid becomes negligible $(\leq 1.5 \%)$ with the increase of $J_{G}$. As a consequence, by neglecting linear pressure 
drop along the riser and along the downcomer, the momentum balance on the entire airlift (Eq. (9)) can also be simplified to

$\left(R_{L d}-R_{L r}\right) \rho_{L} g H \approx \frac{1}{2} \rho_{L} K_{i n f} U_{L d}^{2}$

We can also remind that $R_{L d}=1$ due to the efficiency of the upper gas-liquid separator (see Fig. 1a). Consequently, it is worth to note that the hydrodynamic model (Eqs. (10)-(12)) can be further simplified to the following equation satisfied by $R_{G r}$ :

$\frac{Q_{G}}{A_{r} R_{G r}}=\frac{A_{d} \sqrt{R_{G r} 2 g H / K_{i n f}}+Q_{L P}}{A_{r}\left(1-R_{G r}\right)}+G_{r}$

Solving Eq. (14) gives very similar results than solving the complete model (Eqs. (10)-(12)). Eq. (14) has the advantage to clearly highlight that the closure of the riser slip $G_{r}$ is the key of the modelling of airlift hydrodynamics.

Finally, one can note that in the present model, the average gas volume fraction on a cross-section is considered as constant along the riser. This hypothesis is only reasonable for airlifts of a few meter height (weak hydrostatic pressure effects) and for low mass transfer flux (no bubbles shrinkage), which is the case in our experimental conditions.

\subsection{Drag closure law for a bubble swarm}

In dense cocurrent gas-liquid upflow, it is known from different works that the bubble relative velocity decreases with the increase of the gas volume fraction (Bridge et al., 1964; Wallis, 1969; Rusche and Issa, 2000; Zenit et al., 2001; Garnier et al., 2002; Roig and Larue de Tournemine, 2007; Riboux et al., 2010; Roghair et al., 2011; Colombet et al., 2011). This decrease can be described introducing an hindrance function $f\left(R_{G}\right)$ so that in a first approach the slip velocity in the riser can be given as $G_{r}=f\left(R_{G}\right) V_{z}^{\infty}$, where $V_{z}^{\infty}$ is the single bubble rising velocity.

$V_{z}^{\infty}$ can be estimated from the equilibrium between buoyancy and drag forces $\left(\Delta \rho\left(\pi d_{10}^{3} / 6\right) g=\left(\pi d_{10}^{2} / 4\right) C_{D}^{\infty}(1 / 2) \rho_{L}\left(V_{z}^{\infty}\right)^{2}\right)$ by using the relation proposed recently by Dijkhuizen et al. (2010) for the drag coefficient

$C_{D}^{\infty}=\sqrt{C_{D}\left(R e_{b}\right)^{2}+C_{D}(E o)^{2}}$,

with $C_{D}\left(R e_{b}\right)$ given by the relation of Mei et al. (1994) and $C_{D}(E o)$ given as $C_{D}(E o)=4 E o /(9.5+E o)$. Based on front tracking numerical simulations and experiments (water/glycerine), Eq. (15) is able to describe drag coefficient for spherical and deformed single bubbles. This drag law is also in agreement with previous works of Duineveld (1994) and Veldhuis (2007) for deformed bubbles rising in water at ambient temperature and pressure. As shown in Fig. 5, using relation (15) and fluids properties (Table 1), for $2.5 \leq$ $d_{e q} \leq 20 \mathrm{~mm}$, the single bubble relative velocity stays around $0.25 \mathrm{~m} \mathrm{~s}^{-1}$.

For a cocurrent upward air/water bubbly flow, in a bubble column open to the liquid, by measuring bubbles mean velocity and diameter with a dual-tip optical probe, Garnier et al. (2002) proposed the following expression for $1.6 \leq J_{L} \leq 6.2 \mathrm{~cm} \mathrm{~s}^{-1}$ :

$f\left(R_{G}\right)=\left(1-R_{G}^{1 / 3}\right)$

As a result, the following relation can be taken to estimate bubbles slip velocity in the riser: $G_{r}=\left(1-R_{G}^{1 / 3}\right) V_{z}^{\infty}$ with $V_{z}^{\infty} \approx 0.25 \mathrm{~m} \mathrm{~s}^{-1}$. In Fig. 4, using this closure law, the predicted global gas volume fraction in the riser $R_{G r}$ is compared to measurements for $J_{L}=0$ (dash line indicated with $\gamma=1$ ) and for $J_{L}=6.5 \mathrm{~cm} \mathrm{~s}^{-1}$ (continuous line indicated with $\gamma=1$ ). For both liquid flow rates considered, it can be noticed that the model results are globally in agreement with experimental data at low gas flow rates (low $J_{G}$ ). However, for $J_{G} \geq 2 \mathrm{~cm} \mathrm{~s}^{-1}$, this model overestimates the global gas volume fraction in the riser.

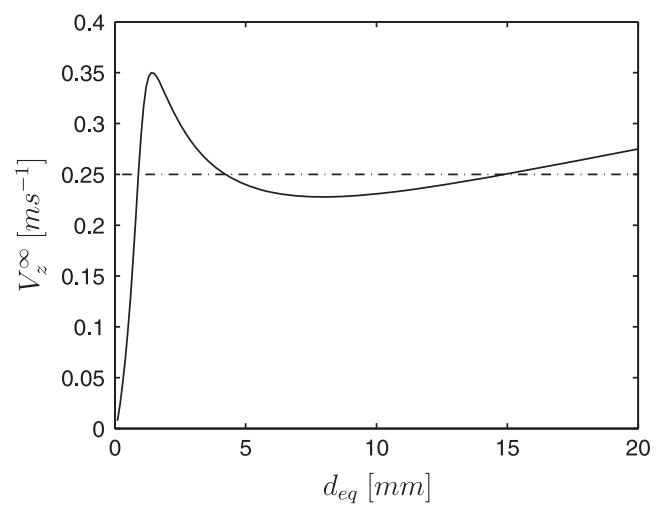

Fig. 5. Evolution of bubble relative velocity for a single bubble of equivalent diameter $d_{e q}:-V_{z}^{\infty}$ from Eq. (15) (Dijkhuizen et al., 2010), -.. $-V_{z}^{\infty}=0.25 \mathrm{~ms}^{-1}$.
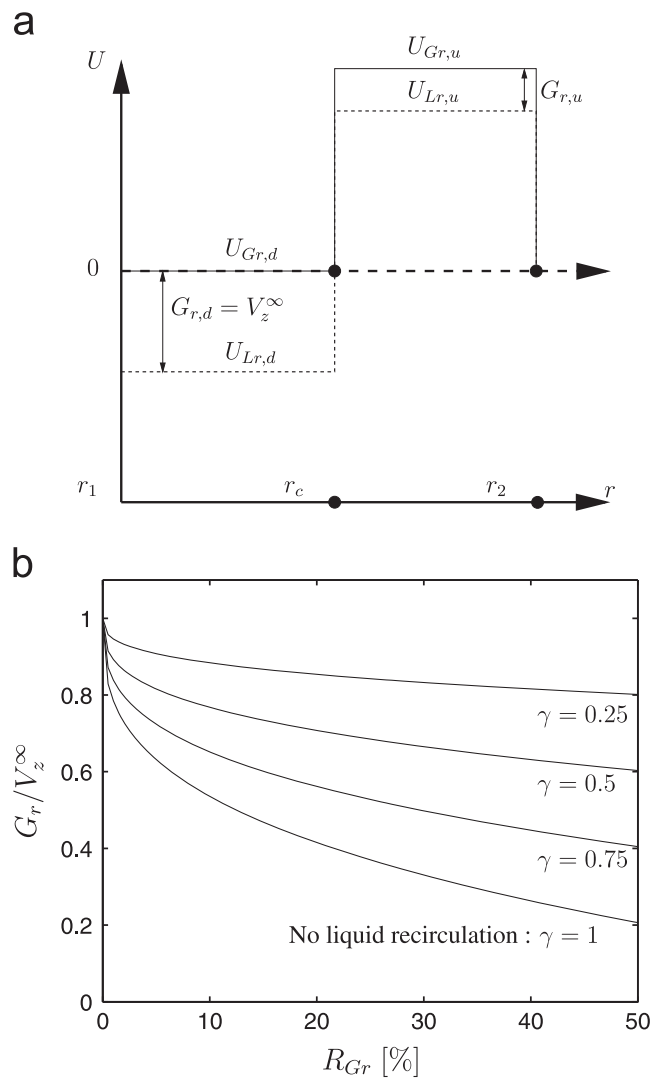

Fig. 6. (a) Representation of spatial volume-fraction-weighted average vertical velocities in the riser for the cross-sectional area between $r_{1}$ and $r_{c}\left(U_{L r, d}, U_{G r, d}\right)$ and for the cross-sectional area between $r_{c}$ and $r_{2}\left(U_{L r, u}, U_{G r, u}\right)$. (b) Slip velocity in the riser for different liquid recirculation sizes $\gamma=A_{r, u} / A_{r}$ (Eq. 19).

\subsection{Effect of large scale recirculation within the riser}

At moderate and high gas flow rates, as suggested by global and local gas volume fraction measurements displayed in Fig. 4 and as reported by Wongsuchoto and Pavasant (2004), this discrepancy can be explained by the formation of a large scale liquid recirculation in the riser. This liquid loop can be characterized by its core radius $r_{c}$ (see Fig. $1 \mathrm{~b}$ ). To take into account the liquid recirculation effect on the mean flow, the spatial volume-fraction-weighted average gas and liquid velocities can be modeled as depicted in Fig. 6a.

Contrary to cocurrent upward flow, it is observed experimentally that bubble rising velocity in dense counter current gas- 
liquid flow corresponds to the velocity of a single bubble (Couvert et al., 2001). In other words, $f\left(R_{G}\right)=1$ is chosen for the countercurrent part of the gas-liquid flow. This phenomena may be explained by an increase of coalescence in such a flow. So far, even if this behavior is not yet well understood, the slip velocity $G_{r, d}$ is assumed to be one of a single bubble, $G_{r, d}=V_{z}^{\infty}$, for the riser volume $r_{1}<r<r_{c}$ (see Fig. 1). Moreover, as done for airlift downcomer models (Cockx et al., 1997; Talvy et al., 2005), we also assume that the bubbles are trapped by the downward liquid flow so that the spatial volume-fraction-weighted average gas velocity is $U_{G r, d}=U_{L r, d}+G_{r, d}=0$. For the riser volume $r_{c}<r<r_{2}$ (see Fig. 1), where the liquid and the gas are both expected to go upward, the slip velocity $G_{r, u}$ can be defined as previously in Section 4.4 as $G_{r, u}=\left(1-R_{G}^{1 / 3}\right) V_{z}^{\infty}$. One shall recall here that velocities considered in the 1D model are spatial volume-fraction-weighted average velocities. As a result the assumption $U_{G r, d}=0$, do not mean that local average velocities of the gas phase $u_{G r, d}$ are zero. This just assumes that the gas flowrate $\left(R_{G r} A_{r, d} U_{G r, d}\right)$ through the crosssectional area between $r_{1}$ and $r_{c}$ is zero.

Consequently, considering spatial average velocities $U$ given in Fig. 6a, in a polar coordinate system, the spatial volume-fractionweighted average gas and liquid velocities for the riser can be written as follows:

$$
\begin{aligned}
U_{G} & =\frac{1}{A_{r}} \int_{\theta=0}^{\theta=2 \pi}(\underbrace{\int_{r=r_{1}}^{r=r_{c}} u_{G r, d} r d r}_{U_{G r, d}=0}+\underbrace{\int_{r=r_{c}}^{r=r_{2}} u_{G r, u} r d r}_{U_{G r, u}}) d \theta \\
& =\gamma\left(U_{L r, u}+V_{z}^{\infty} f\left(R_{G r}\right)\right),
\end{aligned}
$$

$$
U_{L}=\frac{1}{A_{r}} \int_{\theta=0}^{\theta=2 \pi}(\underbrace{\int_{r=r_{1}}^{r=r_{c}} u_{L r, d} r d r}_{U_{L r, d}}+\underbrace{\int_{r=r_{c}}^{r=r_{2}} u_{L r, u} r d r}_{U_{L r, u}}) d \theta
$$$$
=-(1-\gamma) V_{z}^{\infty}+\gamma U_{L r, u} \text {, }
$$

where we introduce $\gamma=A_{r, u} / A_{r}$ as the ratio between the surface area where the liquid flow is upward (i.e. $r_{c}<r<r_{2}$ ) and the total riser surface area $\left(A_{r}\right)$. In other words, $\gamma$ represents the size of the liquid recirculation. Considering both the liquid recirculation size $\gamma$ and the $R_{G r}$-correction on the slip for the upward liquid flow $\left(f\left(R_{G r}\right)\right)$, the resulting slip for the entire riser is thus given as

$G_{r}=U_{G}-U_{L}=V_{z}^{\infty}\left(\gamma f\left(R_{G r}\right)+(1-\gamma)\right)$

Combined with Eq. (16), one gets a very simple relation to take into account the recirculation within the riser $G_{r}=V_{z}^{\infty}\left(1-\gamma R_{G r}^{1 / 3}\right)$. In Fig. $6 \mathrm{~b}, G_{r} / V_{z}^{\infty}$ versus $R_{G r}$ is depicted for different liquid recirculation sizes $\gamma$. As shown in this figure, for a given $R_{G}$, the increase of the liquid recirculation size causes an increase of the riser bubble mean slip velocity $G_{r}$. As a consequence, at the riser scale, the collective effect on the slip velocity (expressed by $f\left(R_{G}\right)$ ) is weakened by the formation of a large scale liquid recirculation in the riser.

The results obtained with this new closure relation have been compared to our experiments in Fig. 4. For low gas flow rates, Eq. (19) gives a good agreement with global measurements considering $\gamma=1$. This is due to the fact that for $\gamma=1$ (no recirculation), Eq. (19) is equivalent to the closure law proposed earlier (Eq. (16)). For moderate and high gas flow rates, it is found that Eq. (19) achieves a better agreement with measurements considering $\gamma=0.5$ instead of $\gamma=1$. This suggests that the size of the liquid recirculation in the riser $(\gamma)$ depends upon the gas flow rate. Indeed, for a given $J_{L P}$, an increase of the gas flow rate results in an increase of the downcomer liquid flow rate $Q_{I d}$ that tends to push the flow in direction to the external wall of the airlift, increasing the recirculation size. This is in agreement with Wongsuchoto and Pavasant (2004) who observed significant liquid recirculation for low downcomer/riser surface area ratio $\left(A_{d} / A_{r} \ll 1\right)$, as in our reactor geometry (Fig. 1a). Moreover, one can note that if $U_{G r, d}$ is slightly positive (negative) this will result in an increase (decrease) of the riser slip velocity $G_{r}$, so that one should considered higher (lower) value for $\gamma$ to reproduce experimental data.

Finally, the model results are reported in Table 2 for different $J_{G}$ and the two $J_{L P}$ considered. According to the model, it is found that the velocity at the top of the draft tube $U_{L s}=Q_{L d} /\left(\pi r_{s}^{2}\right)$ remains always lower than the bubble terminal velocity $\left(V_{z}^{\infty} \approx 0.25 \mathrm{~m} \mathrm{~s}^{-1}\right)$ and the downcomer is then, as expected, not aerated. The present hydrodynamic model enables also to estimate area-weighted average velocities in the riser and in the downcomer $\left(U_{L d}, U_{L r}\right.$, $U_{G r}$ ), as well as recycling rate between the downcomer and the riser $\left(Q_{L d} / Q_{L r}=Q_{L d} /\left(Q_{L d}+Q_{L P}\right)\right)$. In the following, those data are used to performed mass transfer $1 \mathrm{D}$ modelling.

\section{Mass transfer}

The mass transfer experiments were performed for $J_{L P}=$ $6.5 \mathrm{~cm} \mathrm{~s}^{-1}$ and $J_{G}=2.2-4.3-6.5-10.8 \mathrm{~cm} \mathrm{~s}^{-1}$. The volumetric mass transfer coefficient is estimated by solving 1D oxygen concentration transport equations in the gas and the liquid phases. This 1D model is often known as the axial dispersion model (Deckwer et al., 1974; Camacho Rubio et al., 2001; Gourich et al., 2006; Han and Al-Dahhan, 2007; Talvy et al., 2007b). The experimental time evolution of the oxygen concentration measurements, respectively at the inlet $\left(C_{\text {Lrin }}\right.$, $+)$ and at the outlet $\left(C_{\text {Lout }},{ }^{\circ}\right)$ of the riser, are reported in Fig. 7. This figure reveals a significant difference between $C_{\text {Lrin }}$ and $C_{\text {Lout }}$ for each gas flow rate before reaching the liquid saturation. This concentration difference is not only due to the mass transfer but also to the axial transport (advection and dispersion). Thus, to measure and study mass transfer in the airlift, the concentration transport equations of a species have to be introduced. In the following, these equations have been solved numerically by the finite element method $\left(\mathrm{Comsol}^{\mathbb{R}} 3.5 a\right)$ with a direct linear solver (Schenk and Gärtner, 2004).

\subsection{Axial dispersion model}

The transport equation of the mass concentration $C_{k}$ of a species in phase $k$ along the riser can be directly derived by spatially averaging in a cross-section the Euler-Euler two fluid model for the local concentration transport equations. Without chemical reaction, the corresponding 1D equations for gas and liquid phases are given as Talvy et al. (2007b)

$\frac{\partial C_{L r}}{\partial t}+U_{L r} \frac{\partial C_{L r}}{\partial z}=E_{Z L r} \frac{\partial^{2} C_{L r}}{\partial z^{2}}+\frac{k_{L} a_{I}}{R_{L}}\left(m C_{G r}-C_{L r}\right)$

$\frac{\partial C_{G r}}{\partial t}+U_{G r} \frac{\partial C_{G r}}{\partial z}=E_{Z G r} \frac{\partial^{2} C_{G r}}{\partial z^{2}}-\frac{k_{L} a_{I}}{R_{G}}\left(m C_{G r}-C_{L r}\right)$,

with $k_{L}$ the mass transfer coefficient and $a_{I}$ the interfacial area per unit volume. $E_{z k}$ stands for the axial dispersion coefficient of phase $k$. $m$ is a non dimensional coefficient resulting from the Henry's law corresponding approximatively to $m \approx 0.033$ for our gas-liquid system. In order to be able to deduce the volumetric mass transfer coefficient $k_{\mathrm{L}} a_{I}$ from the measurements reported in Fig. 7, it is necessary to estimate the axial mixing in the riser $\left(E_{Z G r}, E_{Z L r}\right)$.

\subsection{Axial mixing in the riser}

In the gas phase, the axial dispersion coefficient $E_{Z G r}$ can be related to the large velocity differences between bubbles of different 

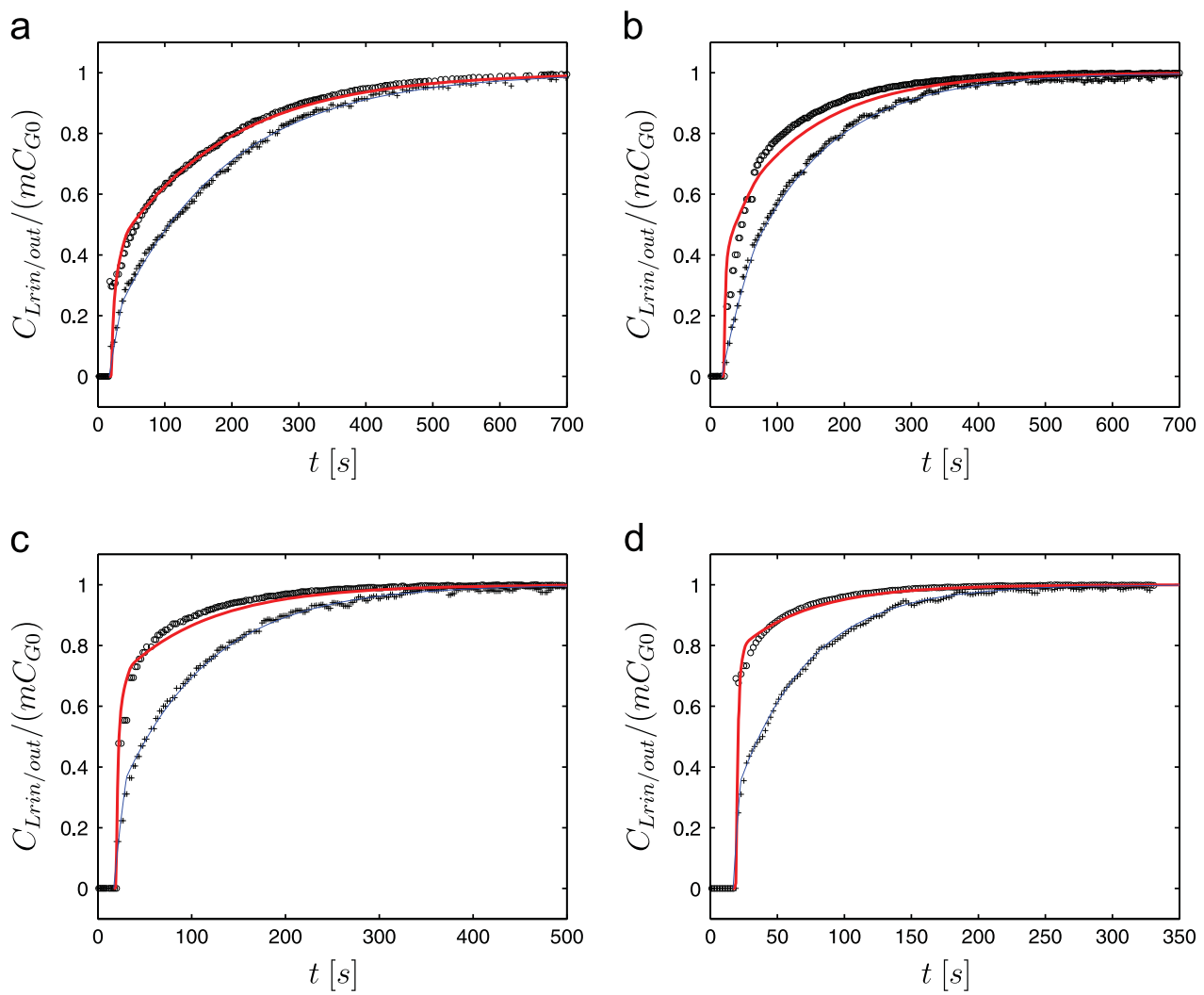

Fig. 7. (Color online) Oxygen concentration at the riser inlet $C_{L r i n}$ and at the riser outlet $C_{L r o u t}$ for $J_{G}=$ (a) 2.2 (b) 4.3 (c) 6.5 (d) $10.8 \mathrm{~cm} \mathrm{~s}^{-1}$ and $J_{L P}=6.5 \mathrm{~cm} \mathrm{~s}^{-1}$; Exp. data: + $C_{\text {Lrin }}$ and $\circ C_{\text {Lrout }} ;-C_{\text {Lrin }}$ described by $C_{\text {Lrin }} / m C_{G 0}=\min [(1-\exp (-(t+c) / a)),(1-\exp (-t / b))]$; $-C_{\text {Lrout }}$ ADM results.

sizes, as for drop dispersions (Bardin-Monnier et al., 2003). Here, we have shown that the bubbles in our experiments have a very similar relative velocity so that $E_{Z G r}$ can be neglected.

In the liquid phase, the axial dispersion $E_{Z L r}$ is mainly influenced by the bubble induced agitation that increases with $R_{G}$ (Riboux et al., 2010) and by the large scale liquid recirculation (Radl and Khinast, 2010). The ADM has been first used to estimate the axial dispersion coefficient in the riser $E_{Z L r}$ from several RTD measurements. For that purpose, the downcomer was modeled as a perfect plug flow (i.e $E_{Z L d}=0$ ) due to the non-aeration of the downcomer.

\subsubsection{Boundary and initial conditions}

Numerically, the injection of the tracer pulse is performed by an initial step of concentration $C_{L r}$ on a thin section at the near bottom of the riser. Moreover, since the inlet flow of fresh water at the bottom of the reactor dilutes the concentration coming down from the downcomer, the riser inlet liquid concentration $C_{L r}$ is given as $C_{L r}(t, z=0)=\left(Q_{L d} / Q_{L r}\right) C_{L d}(t, z=0)$. The transport equation (Eq. (20)) in the liquid phase is then solved to simulate the RTD in the case of a tracer that does not transfer between the phases $\left(k_{L}=0\right)$.

\subsubsection{Comparison with RTD experiments}

In Fig. 8, the 1D model is compared to RTD measurements for $J_{L P}=6.5 \mathrm{~cm} \mathrm{~s}^{-1}$ with $J_{G}=2.2$ and $10.8 \mathrm{~cm} \mathrm{~s}^{-1}$. The estimation of the riser Péclet number $P e_{r}=U_{L r} H / E_{Z L r}$ is performed using the least-squares method by minimizing the sum of squared residuals between experimental and model curves. The best agreement between the RTD experiments and the numerical results from Eq. (20) is found with $P e_{r}=5.8$ for $J_{G}=2.2 \mathrm{~cm} \mathrm{~s}^{-1}$ and with $P e_{r}=7.1$ for $J_{G}=10.8 \mathrm{~cm} \mathrm{~s}^{-1}$. Such low Péclet numbers indicates that the liquid mixing in the riser is very efficient because of the formation of the liquid recirculation inside the riser itself. The 1D model is also reported in Fig. 8 for $P e_{r}=50$. The comparison with $P e_{r}=5.8$ and $P e_{r}=7.1$ indicates that the mixing is so strong in the riser that it is not even possible to measure clearly a second concentration local maximum in our experiments. In the following, an average value of $P e_{r}=6.4$ is considered to estimate the riser axial dispersion for the intermediate gas flow rates $J_{G}=4.3$ and $6.5 \mathrm{~cm} \mathrm{~s}^{-1}$.

\subsection{Mass transfer}

We now consider the oxygen concentration modelling in the gas and liquid phases along the riser (Eq. (20) and (21) with $\left.E_{Z G r}=0\right)$.

\subsubsection{Boundary and initial conditions}

In order to estimate $k_{\mathrm{L}} a_{I}$ with the ADM in our experiments, it is necessary to supply the time evolution of the oxygen concentration at the riser inlet $C_{\text {Lrin }}$ (see Fig. 1a). $C_{\text {Lrin }}$ is considered as the boundary condition used to simulate mass transfer along the riser. As shown in Fig. 7, the riser inlet concentration time evolution $(+)$ can be simply described as $C_{L \text { rin }} /\left(m C_{G 0}\right)=\min [(1-\exp (-(t+c) / a)),(1-\exp (-t / b))]$ where $a, b$ and $c$ are constants. Using this empirical equation to describe oxygen increase at the riser inlet, Eqs. (20) and (21) are solved for the riser only with the following initial conditions: $C_{G r}(t=$ $0, z>0)=0, C_{L r}(t=0, z>0)=0$ and the following boundary conditions for the gas concentration at the riser inlet: $C_{G r}(\forall t, z=0)=C_{G 0}$. At the riser outlet, for gas and liquid concentrations, a boundary condition of convective flux is imposed.

\subsubsection{Volumetric mass transfer coefficient}

The estimation of $k_{L} a_{I}$ is performed using the least-squares method by minimizing the sum of squared residuals between the 

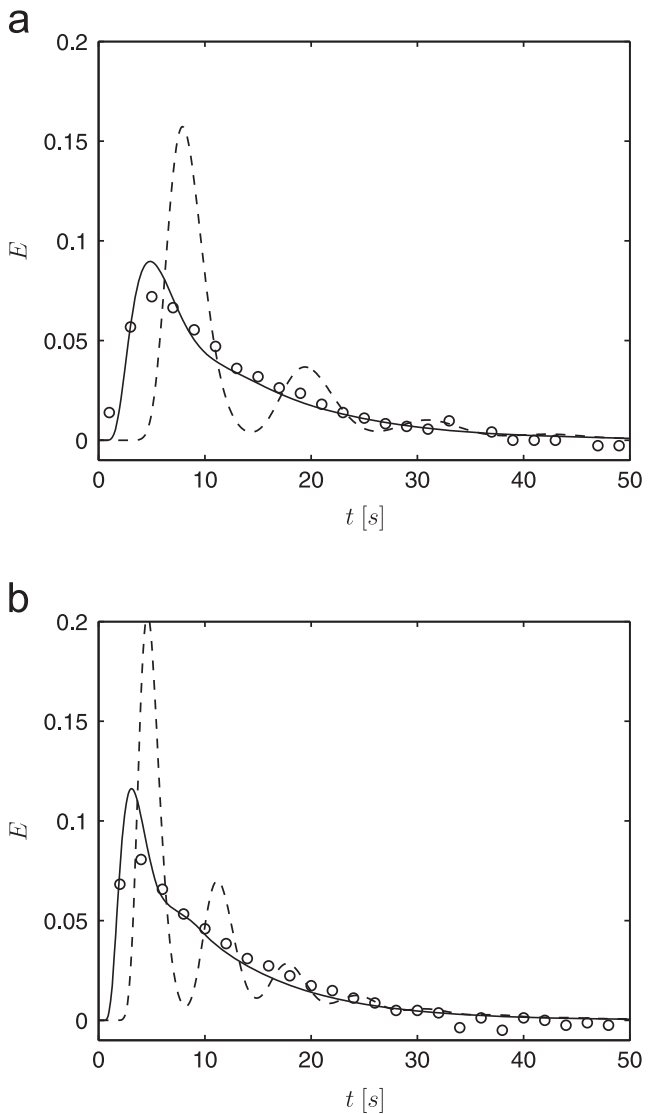

Fig. 8. Residence time distribution with (a) $J_{G}=2.2 \mathrm{~cm} \mathrm{~s}^{-1}$ and (b) $J_{G}=10.8 \mathrm{~cm} \mathrm{~s}^{-1}$ for $J_{L P}=6.5 \mathrm{~cm} \mathrm{~s}^{-1}$ : $\circ$ Exp. data; ADM results for - (a) $P e_{r}=5.8$ and (b) $P e_{r}=7.1$. ADM results for $--P e_{r}=50\left(E=C_{T} / \int_{0}^{\infty} C_{T} d t\right)$.

experimental and the model curves for $C_{\text {Lrout }}$. The 1D model results presented in Fig. 7 show a good agreement with experimental measurements ( $C_{\text {Lrout }}$ thickest continuous lines).

The corresponding $k_{L} a_{I}$ measurements are presented in Fig. $9(\bullet)$ versus $J_{G}$. As shown in this figure and in Table 4 , the volumetric mass transfer coefficient is found to increase from $0.05 \mathrm{~s}^{-1}$ up to $0.23 \mathrm{~s}^{-1}$ when $R_{G r}$ varies from 9.6 to $29 \%$. These results are compared in Fig. 9 with the work of Botton et al. (1980) (Table 4). With a chemical technique (sodium sulphite) to measure volumetric mass transfer coefficient $k_{L} a_{I}$, Botton et al. (1980) performed experiments of oxygen transfer in water for an annulus sparged draft tube airlift reactor and for a liquid superficial velocity of $J_{L P}=3.7 \mathrm{~cm} \mathrm{~s}^{-1}$, with a very similar reactor design $\left(A_{d} \ll A_{r}, r_{1}=0.07 \mathrm{~m}, r_{2}=0.24 \mathrm{~m}\right)$. As reported in Fig. 9, their experimental results $(\square)$ give the same order of magnitude than our measurements with $0.04 \leq k_{L} a_{I} \leq$ $0.14 \mathrm{rms}^{-1}$ for $3.2 \leq J_{G} \leq 8.8 \mathrm{~cm} \mathrm{~s}^{-1}$.

Our results can also be compared to literature correlations for $k_{L} a_{I}$. For mass transfer of oxygen in bubble columns for different liquids, Deckwer et al. (1983) found the following relation:

$k_{L} a_{I}=0.467 J_{G}^{0.82}$,

for $1 \leq J_{L} \leq 11 \mathrm{~cm} \mathrm{~s}^{-1}$ and $0.5 \leq J_{G} \leq 15 \mathrm{~cm} \mathrm{~s}^{-1}$. One can also quote the empirical correlation proposed by Hikita et al. (1981) (Eq. (23)) for $k_{L} a_{I}$, in non electrolyte solutions

$\frac{k_{L} a_{I} J_{G}}{g}=14.9\left(\frac{\mu_{L}}{\rho_{L} D_{L}}\right)^{-0.604}\left(\frac{J_{G} \mu_{L}}{\sigma}\right)^{1.76}\left(\frac{\mu_{L}^{4} g}{\rho_{L} \sigma^{3}}\right)^{-0.284}\left(\frac{\mu_{G}}{\mu_{L}}\right)^{0.243}$

This correlation has been established for small scale bubble columns $\left(D_{c}=0.10-0.19 \mathrm{~m}, H=0.13-0.22 \mathrm{~m}\right)$, with different gas-liquid

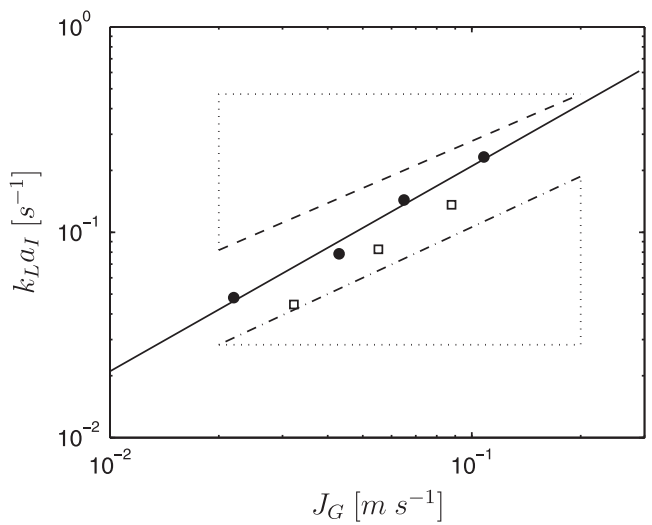

Fig. 9. Global mass transfer coefficient $k_{L} a_{I}$ versus $J_{G}$; $\bullet$ this work: Exp. measurements with ADM; -.- $k_{L} a_{I} \propto J_{G}^{0.82}$ (Deckwer et al., 1983), $--k_{L} a_{I} \propto J_{G}^{0.76}$ (Hikita et al., 1981), $-k_{L} a_{I} \propto J_{G}$; $\square$ Exp. from Botton et al. (1980).

Table 4

Mass transfer results for $J_{L P}=6.5 \mathrm{~cm} \mathrm{~s}^{-1}$.

\begin{tabular}{llllllll}
\hline \multicolumn{2}{l}{ This work } & & & & & \multicolumn{2}{c}{ Botton et al. (1980) } \\
$J_{G}$ & $R_{G r}$ & $P e_{r}$ & $k_{\mathrm{L}} a_{I}$ & $a_{I}$ & $k_{\mathrm{L}} a_{I} / a_{I}$ & $J_{G}$ & $k_{L} a_{I}$ \\
$\mathrm{~cm} \mathrm{~s}^{-1}$ & $\%$ & - & $\mathrm{s}^{-1}$ & $\mathrm{~m}^{-1}$ & $\times 10^{-4} \mathrm{~ms}^{-1}$ & $\mathrm{~cm} \mathrm{~s}^{-1}$ & $\mathrm{~s}^{-1}$ \\
2.2 & 9.6 & 5.8 & 0.0480 & 82.3 & 5.8 & 3.2 & 0.0445 \\
4.3 & 16.7 & - & 0.0785 & 143.1 & 5.5 & 5.5 & 0.0825 \\
6.5 & 20.8 & - & 0.1435 & 178.3 & 8.0 & 8.8 & 0.1360 \\
10.8 & 29.0 & 7.1 & 0.2325 & 248.6 & 9.4 & - & - \\
\hline
\end{tabular}

systems (air, oxygen, methane, hydrogen, carbon dioxide/water, butanol, methanol). According to Eq. (22) the volumetric mass transfer coefficient should evolves as $k_{L} a_{I} \propto J_{G}^{0.82}$ while Eq. (23) predicts a very similar trend $k_{L} a_{I} \propto J_{G}^{0.76}$. As reported in Fig. 9, those two trends are very close to our experimental trend $k_{L} a_{I} \propto J_{G}$.

In the following section, the effect of the gas volume fraction on the mass transfer coefficient is investigated. These coefficients measured in a swarm are then discussed in the light of single bubble mass transfer results.

\subsection{Effect of gas volume fraction on the mass transfer coefficient}

We have estimated the mass transfer coefficient $k_{L}$ for the bubbles in the swarm by calculating the ratio $k_{L} a_{I} / a_{I}$. Since the Sauter mean diameters are nearly the same whatever the gas flow rate (see Table 2), the interfacial area $a_{I}$ can be estimated as $a_{I} \approx 6 R_{G r} / d_{32}$ with $d_{32}=7 \mathrm{~mm}$. In Fig. $10, k_{L} a_{I} / a_{I}$ is plotted $(\bullet)$ versus the riser gas volume fraction $R_{G r}$. The ratio $k_{L} a_{I} / a_{I}$ is found to weakly increase with $R_{G r}\left(5.4 \times 10^{-4} \leq k_{L} a_{I} / a_{I} \leq 9.3 \times 10^{-4} \mathrm{~ms}^{-1}\right)$ and its value remains of the order of $7 \times 10^{-4} \mathrm{~ms}^{-1}$. As reported by Colombet et al., 2011, the mass transfer coefficient at the bubble scale seems to be not drastically affected by the increase of gas volume fraction $R_{G r}$ (or by the increase of $J_{G}$ ). The experimental value for $k_{L}$ is compared with some models. The mass transfer for a single spherical clean bubble can be calculated from the Sherwood number analytical solution obtained by Boussinesq (1905)

$S h=\frac{2}{\sqrt{\pi}} P e^{1 / 2}$,

considering the potential flow around a spherical bubble. This solution is obtained by considering that the flow is potential and that the concentration boundary layer thickness is much smaller than the bubble diameter, assumptions valid at large Reynolds numbers and at large Péclet numbers, respectively. The Boussinesq 


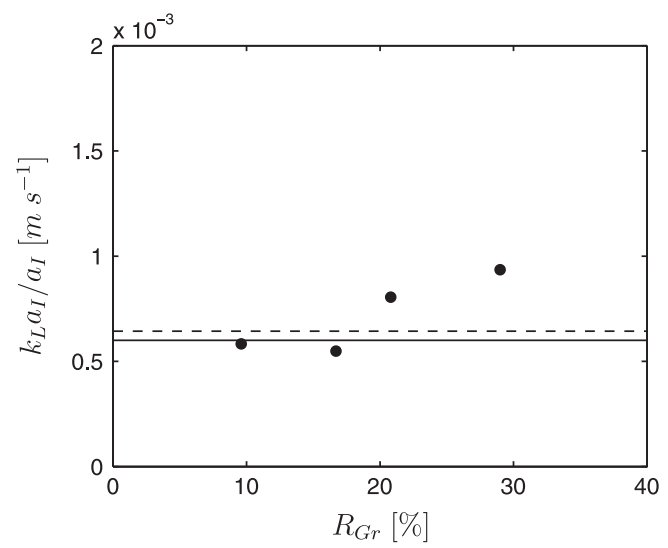

Fig. 10. Evolution of $k_{L} a_{I} / a_{I}$ versus $R_{G r}$ : • this work; $k_{L}$ from -- Eq. (24) (Boussinesq, 1905) and - Eq. (25) (Winnikow, 1967) for $d_{10}=2 \mathrm{~mm}$ and $V_{z}=0.25 \mathrm{~ms}^{-1}$.

solution is known to be very accurate to describe mass transfer for the case of isolated clean spherical bubbles (Figueroa and Legendre, 2010). Note that the Boussinesq solution is equivalent to the wellknown (Higbie, 1935) penetration theory with a contact time based on the bubble equivalent diameter and bubble rising velocity $\left(t_{c}=d_{10} / V_{z}\right)$.

We also consider the solution obtained by Winnikow (1967) and valid for intermediate bubble Reynolds numbers (Figueroa and Legendre, 2010):

$S h=\frac{2}{\sqrt{\pi}}\left(1-\frac{2.89}{\sqrt{R e_{b}}}\right)^{1 / 2} P e^{1 / 2}$

The mass transfer coefficients $k_{L}=S h D_{L} / d_{10}$ deduced from Eqs. (24) and (25) have been compared in Fig. 10 to our experimental data for the mean bubble size measured $d_{10}=2 \mathrm{~mm}$ and an average rising velocity $V_{z}=0.25 \mathrm{~ms}^{-1}$ (see Table 2 ). As shown in this figure, the mass transfer coefficients given by Eq. (24) $\left(k_{L}=6.4 \times 10^{-4} \mathrm{~ms}^{-1}\right)$ and by Eq. $(25)\left(k_{L}=6.0 \times 10^{-4} \mathrm{~ms}^{-1}\right)$ are found to be very close to the experimental ratio $k_{L} a_{I} / a_{I}$. For all the void fractions considered, our results are in good agreement with the relations of Boussinesq (1905) and Winnikow (1967) obtained for a single bubble, especially for $R_{G r}=9.6$ and $16.7 \%$. As reported by Colombet et al., 2011, this results is the combination of two mechanisms. First, the mass transfer takes place in a very thin diffusion layer $\delta_{D}$ located on the front part of the bubble at high Péclet number (Figueroa and Legendre, 2010). Indeed, the diffusion layer can be estimated as $\delta_{D} / d_{10} \approx P e^{-1 / 2} \approx 0.002$ for $d_{10}=2 \mathrm{~mm}$ and $P e=R e_{b} S c \approx 1.9 \times 10^{5}$. Thus $\delta_{D} \approx 5 \mu \mathrm{m}$ so that the diffusion layer remains very small compared with the bubble's diameter and with the distance between bubbles. Second, the mean flow field near the bubble interface is not significantly affected by the bubble induced agitation for the void fraction considered here (Roig and Larue de Tournemine, 2007). It results in a transfer not significantly affected as regards to the range of volume fraction considered $\left(R_{G r} \leq 30 \%\right)$.

However, for the experiments at $R_{G r}=21 \%$ and $R_{G r}=29 \%$, the experimental ratios $k_{L} a_{I} / a_{I}$ are around $40 \%$ higher than the $k_{L}$ values provided by Eq. (25) and by the Boussinesq's solution (Eq. (24)). For these two experiments at higher gas flow rates, one first explanation for the difference can be attributed to the interfacial area $a_{I}$ that is underestimated by the intense formation of very thin bubbles having a diameter smaller than the smallest measurable diameter by the optical probe $\left(d_{e q}<0.1 \mathrm{~mm}\right)$. Very thin bubbles are difficult to be pierced properly, and even pierced they have a strong interaction with the forward tip (Vejrazka et al.,
2010). Meanwhile, the mass transfer measurements take into account the whole real bubble population, including the smaller ones.

A second explanation for those discrepancies may be indirectly the effect of the appearance of the liquid loop in the riser. Indeed if a part of very small bubbles are trapped by the additional liquid loop and recirculate inside the riser this may tend to make longer bubble residence time leading to higher mass transfer.

Finally, we need to mentioned here that while increasing the gas volume fraction, bubble coalescence can occur under the increase of collision frequency between bubbles. Strong coalescence can changed interfacial area per unit volume $\left(a_{I}\right)$, mass transfer coefficient of bubbles $\left(k_{L}\right)$ and dispersion of the oxygen concentration in the gas phase $\left(E_{Z G r}\right)$. In the present work, the effect of coalescence has not been taken into account since it stays very difficult to quantify the intensity of this phenomena in such bubbly flow and even more its effect on mass transfer.

\section{Conclusions}

In this work, one-dimensional modelling of hydrodynamics and mass transfer is applied to study an annulus sparged draft tube airlift reactor of a semi-industrial size. The classical airlift global model (Talvy et al., 2007a,b) is modified to account for the particular hydrodynamics of such airlifts at high gas throughputs. The first modification is to consider the decrease of the riser slip velocity with the increase of gas volume fraction for cocurrent gasliquid upflow $\left(\left(1-R_{G}^{1 / 3}\right) V_{z}^{\infty}\right)$. The second improvement consists in introducing an original closure relation to describe the effect of the liquid loop in the riser via the recirculation surface ratio $\gamma$ on the mean bubble slip velocity $\left(G_{r}=V_{z}^{\infty}(1-\gamma) R_{G}^{1 / 3}\right)$. Using this closure law for slip velocity the $1 \mathrm{D}$ hydrodynamic model reproduces well macroscale experiments regardless the bubble population is very spread due to a jet regime at the sparger.

Then, mass transfer in the airlift reactor has been studied. As in Hikita et al. (1981) or Deckwer et al. (1983) for bubble columns, the measured volumetric mass transfer coefficient is found to vary quite linearly with the gas superficial velocity. The ratio $k_{L} a_{I} / a_{I}$ stays of the order of $k_{L} a_{I} / a_{I} \approx 7 \times 10^{-4} \mathrm{~ms}^{-1}$ for $9.6 \leq R_{G r} \leq 29.0 \%$. The mass transfer at the bubble scale is not significantly modified by an increase of the gas volume fraction at high Péclet number in agreement with Colombet et al. (2011). The direct comparison of the ratio $k_{L} a_{I} / a_{I}$ with transfer models for single spherical bubble shows a good agreement with experimental data at moderate gas volume fraction. At high gas flow rate, the mass transfer coefficient seems to be a bit higher probably because very small bubbles play a key role in the mass transfer but are not detected by optical probes or may recirculate inside the riser.

From an industrial point of view, this 1D global model permits to study the effect of varying airlift geometrical dimensions on hydrodynamic and mass transfer. That global model is also a powerful tool for engineering design of airlift contactors and can be easily completed by introducing chemical reaction kinetics. To go further in the analysis of mass transfer results, a near-future perspective is to study mass transfer for very dense bubble swarm in a simpler geometry in order to focus on the bubble population effects.

\section{Nomenclature}

Roman symbols
$\begin{array}{ll}\text { cross sectional area, } \mathrm{m}^{2} \\ a_{I} & \text { interfacial area per unit volume, } \mathrm{m}^{-1} \\ a_{p}^{I} & \text { projected interfacial area per unite volume, } \mathrm{m}^{-1} \\ C_{G 0} & \text { oxygen mass concentration in dry air, } \mathrm{mg} \mathrm{L}^{-1} \\ C_{k} & \text { mass concentration in phase } k, \mathrm{mg} \mathrm{L}^{-1}\end{array}$


mass concentration at the riser inlet $C_{\text {Lrin }}=C_{L r}(z=0)$, $\mathrm{mg} \mathrm{L}^{-1}$

$C_{\text {Lrout }}$ mass concentration at the riser outlet $C_{\text {Lrout }}=C_{L r}(z=H)$, $\mathrm{mg} \mathrm{L}^{-1}$

$C_{T} \quad$ tracer mass concentration, $\mathrm{mg} \mathrm{L}^{-1}$

$d_{e q} \quad$ volume equivalent diameter, $m$

$d_{10} \quad$ mean equivalent diameter $d_{10}=\left\langle d_{e q}\right\rangle, \mathrm{m}$

$d_{32} \quad$ Sauter mean diameter, $m$

$D_{L} \quad$ molecular diffusivity in the liquid, $\mathrm{m}^{2} \mathrm{~s}^{-1}$

$E_{z} \quad$ axial dispersion coefficient, $\mathrm{m}^{2} \mathrm{~s}^{-1}$

$E_{o} \quad$ bubble Eötvös number $E_{o}=\Delta \rho g d_{10}^{2} / \sigma$

$g$ gravity constant, $g=9.81 \mathrm{~m} \mathrm{~s}^{-2}$

$G \quad$ slip velocity between gas and liquid phases, $\mathrm{m} \mathrm{s}^{-1}$

$G_{r, d}$ slip velocity in the riser for counter current gas-liquid flow, $\mathrm{m} \mathrm{s}^{-1}$

$G_{r, u}$ slip velocity in the riser for cocurrent gas-liquid flow, $\mathrm{m} \mathrm{s}^{-1}$

$H$ airlift reactor height, $m$

$\mathrm{He} \quad$ Henry's constant for oxygen in water, $\mathrm{Pa}$

$J_{G} \quad$ superficial gas velocity $J_{G}=Q_{G} / A_{r}, \mathrm{~m} \mathrm{~s}^{-1}$

$J_{L P} \quad$ superficial liquid velocity $J_{L P}=Q_{L P} / A_{r}, \mathrm{~m} \mathrm{~s}^{-1}$

$K \quad$ pressure drop coefficient

$k_{L} \quad$ liquid-side mass transfer coefficient, $\mathrm{m} \mathrm{s}^{-1}$

$k_{L} a_{I} \quad$ global mass transfer coefficient, $\mathrm{m} \mathrm{s}^{-1}$

$L_{k}^{w} \quad$ perimeter of the wall wetted by phase $k, \mathrm{~m}$

$m$ coefficient resulting from Henry's law

$M_{i} \quad$ molar mass of species $i, \mathrm{~kg} \mathrm{~mol}^{-1}$

$N_{b} \quad$ number of bubbles in $V_{G+L}$

$P$ pressure, $\mathrm{Pa}$

$\mathrm{Pe} \quad$ bubble Péclet number $\mathrm{Pe}=\mathrm{ScRe} e_{b}$

$P e_{r} \quad$ riser Péclet number $P e_{r}=U_{L r} H / E_{Z L r}$

$Q_{G}$ gas volume flow rate in the riser, $\mathrm{m}^{3} \mathrm{~s}^{-1}$

$Q_{L d} \quad$ liquid volume flow rate in the downcomer, $\mathrm{m}^{3} \mathrm{~s}^{-1}$

$Q_{L r} \quad$ liquid volume flow rate in the riser, $\mathrm{m}^{3} \mathrm{~s}^{-1}$

$Q_{L P}$ reactor inlet liquid volume flow rate (in the riser), $\mathrm{m}^{3} \mathrm{~s}^{-1}$

$r$ geometrical radius, $m$

$R_{k} \quad$ global volume fraction

$R e_{b} \quad$ bubble Reynolds number $R e_{b}=V_{z} d_{10} / \nu_{L}$

Sh Sherwood number

$S_{b} \quad$ bubble surface, $\mathrm{m}^{2}$

Sc Schmidt number $S c=\nu_{L} / D_{L}$

$T$ temperature, ${ }^{\circ} \mathrm{C}$

$u \quad$ local velocity, $\mathrm{m} \mathrm{s}^{-1}$

$U$ spatial volume-fraction-weighted average velocity, $\mathrm{m} \mathrm{s}^{-1}$

$V_{b} \quad$ bubble volume, $\mathrm{m}^{3}$

$V_{z}^{\infty} \quad$ rising terminal velocity of a single bubble, $\mathrm{m} \mathrm{s}^{-1}$

$V_{\text {Tank }}$ buffer tank volume, $\mathrm{m}^{3}$

We bubble Weber number $W e=\rho_{L} V_{z}^{2} d_{10} / \sigma$

Greek symbols

$\alpha_{G} \quad$ local gas volume fraction

$\chi \quad$ bubble aspect ratio

$\delta_{D} \quad$ diffusion layer thickness, $\mathrm{m}$

$\gamma \quad$ recirculation surface ratio $\gamma=A_{r, u} / A_{r}$

$\mu \quad$ dynamic viscosity of phase $k$, Pa s

$\nu \quad$ kinematic viscosity of phase $k, \mathrm{~m}^{2} \mathrm{~s}^{-1}$

$\rho$ density of phase $k, \mathrm{~kg} \mathrm{~m}^{-3}$

$\sigma \quad$ surface tension, $\mathrm{N} \mathrm{m}^{-1}$

$\tau^{I} \quad$ interfacial stress, $\mathrm{N} \mathrm{m}^{-2}$

$\tau^{w} \quad$ wall shear stress, $\mathrm{N} \mathrm{m}^{-2}$

\section{Subscripts}

d referring to the downcomer

$G$ gas phase

$k$ referring to the liquid or gas phase
$\begin{array}{ll}L & \text { liquid phase } \\ r & \text { referring to the riser } \\ S & \text { separator }\end{array}$

\section{Acknowledgments}

This work was initiated by previous experimental investigations at RHODIA R\&D Center in Saint-Fons, France. Authors would like to thank RHODIA, member of the SOLVAY Group, for supporting this work and especially E. Cotton, D. Petitqueux and Dr. C. Daniel. This research was carried out within the framework of a CIFRE-ANRT contract in collaboration with the FERMaT federation.

\section{References}

Bardin-Monnier, N., Guiraud, P., Gourdon, C., 2003. Lagrangian simulations contribution to the knowledge of discs and doughnuts pulsed solvent extraction columns hydrodynamics. Chemical Engineering and Processing 42, 503-516.

Becker, S., Sokolichin, A., Eigenberger, G., 1994. Gas-liquid flow in bubble columns and loop reactors: Part II: comparison of detailed experiments and flow simulations. Chemical Engineering Science 49 (24), 5747-5762.

Bello, R.A. 1981. A Characterization Study of Airlift Contactors for Application to Fermentation. Ph.D. Thesis, Waterloo University, Ontario, USA.

Botton, R., Cosserat, D., Charpentier, J.C., 1978. Influence of column diameter and high gas throughputs on the operation of a bubble column. The Chemical Engineering Journal 16, 107-115.

Botton, R., Cosserat, D., Charpentier, J.C., 1980. Mass transfer in bubble columns operating at high gas throughputs. The Chemical Engineering Journal 20 (2), 87-94.

Boussinesq, J., 1905. Calcul du pouvoir refroidissant des courants fluides. Journal des Mathematiques Pures et Appliquees 6, 285-332.

Bridge, A., Lapidus, L., Elgin, J., 1964. The mechanics of vertical gas-liquid fluidized system I: countercurrent flow. AIChE Journal 10 (6), 819-826.

Camacho Rubio, F., Garcia, J.L., Molina, E., Chisti, Y., 2001. Axial inhomogeneities in steady-state dissolved oxygen in airlift bioreactors: predictive models. Chemical Engineering Journal 84 (1), 43-55.

Camarasa, E., Vial, C., Poncin, S., Wild, G., Midoux, N., Bouillard, J., 1999. Influence of coalescence behaviour of the liquid and of gas sparging on hydrodynamics and bubble characteristics in a bubble column. Chemical Engineering and Processing 38, 329-344.

Cartellier, A., 1999. Post-treatment for phase detection probes in non uniform twophase flows. International Journal of Multiphase Flow 25 (2), 201-228.

Chisti, Y., 1989. Airlift Bioreactors. Elsevier, New York.

Chisti, Y., Moo-Young, M., 1993. Improve the performance of airlift reactors. Chemical Engineering Progress 89 (6), 38-45.

Chisti, Y., Wenge, F., Moo-Young, M., 1995. Relationship between rise and downcomer gas hold-up in internal airlift reactors without gas-liquid separators. The Chemical Engineering Journal 57, B7-B13.

Clark, N.N., Turton, R., 1988. Chord length distributions related to bubble size distributions in multiphase flows. International Journal of Multiphase Flow 14 (4), 413-424.

Cockx, A., Liné, A., Roustan, M., Do-Quang, Z., Lazarova, V., 1997. Numerical simulation and physical modeling of the hydrodynamics in an air-lift internal loop reactor. Chemical Engineering Science 52, 3787-3793.

Colin, C. Fabre, J., McQuillen, J., 1996. Bubble and slug flow at microgravity conditions: state of knowledge and open questions. Chemical Engineering Communications 141-142 (1), 155-173.

Colombet, D., Legendre, D., Cockx, A., Guiraud, P., Risso, F., Daniel, C., Galinat, S. 2011. Experimental study of mass transfer in a dense bubble swarm. Chemical Engineering Science 66 (14), 3432-3440.

Couvert, A., Bastoul, D., Roustan, M., Liné, A., Chatellier, P., 2001. Prediction of liquid velocity and gas hold-up in rectangular air-lift reactors of different scales. Chemical Engineering and Processing 40 (2), 113-119.

Deckwer, W.D., Burckhart, R., Zoll, G., 1974. Mixing and mass transfer in tall bubble columns. Chemical Engineering Science 29 (11), 2177-2188.

Deckwer, W.D., Nguyen-Tien, K., Kelkar, B.G., Shah, Y.T., 1983. Applicability of axia dispersion model to analyse mass transfer measurements in bubble columns. AIChE Journal 29 (6), 915-922.

Dijkhuizen, W., Roghair, I., Van Sint Annaland, M. Kuipers, J.A.M. 2010. DNS of gas bubbles behaviour using an improved $3 \mathrm{~d}$ front tracking model-drag force on isolated bubbles and comparison with experiments. Chemical Engineering Science 65 (4), 1415-1426.

Duineveld, P.C., 1994. Bouncing and Coalescence of Two Bubbles in Water. Ph.D. thesis, Twente University, Netherlands. 
Figueroa, B., Legendre, D., 2010. Mass or heat transfer from spheroidal gas bubbles rising through a stationary liquid. Chemical Engineering Science 65, 6296-6309.

Garnier, C., Lance, M., Marié, J.L., 2002. Measurement of local flow characteristics in buoyancy-driven bubbly flow at high void fraction. Experimental Thermal and Fluid Science 26, 811-815.

Gourich, B., EL Azher, N., Soulami Bellhaj, M., Delmas, H., Bouzidi, A., Ziyad, M., 2005. Contribution to the study of hydrodynamics and gas-liquid mass transfer in a two- and three-phase split-rectangular airlift reactor. Chemical Engineering and Processing 168, 1325-1333.

Gourich, B., Vial, C., El Azher, N., Belhej Soulami, M., Ziyad, M., 2006. Improvement of oxygen mass transfer estimation from oxygen concentration measurements in bubble column reactors. Chemical Engineering Science 61, 6218-6222.

Habrdova, K., Hovorka, S., Bartovska, L., 2004. Concentration dependence of surface tension for very dilute aqueous solutions of organic nonelectrolytes. Journal of Chemical Engineering Data 49, 1003-1007.

Han, L., Al-Dahhan, M.H., 2007. Gas-liquid mass transfer in a high pressure bubble column reactor with different sparger designs. Chemical Engineering Science $62,131-139$

Herringe, R., Davis, M., 1976. Structural development of gas-liquid mixture flows. Journal of Fluid Mechanics 73 (1), 97-123.

Higbie, R., 1935. The rate of absorption of a pure gas into a still liquid during short periods of exposure. Transactions of the American Institute of Chemical Engineers 31, 365-389.

Hikita, H., Asai, S., Tanigawa, K., Segawa, K., Kitao, M., 1981. The volumetric liquidphase mass transfer coefficient in bubble columns. Chemical Engineering Journal 22, 61-69.

Jones, A.G., 1985. Liquid circulation in a draft-tube bubble column. Chemical Engineering Science 40, 449-462.

Kojima, H., Sawai, J., Uchino, H., Ichige, T., 1999. Liquid circulation and critical gas velocity in slurry bubble column with short size draft tube. Chemical Engineering Science 54 (21), 5181-5185.

Kushalkar, K.B., Pangarkar, V.G., 1994. Particle-liquid mass transfer in a bubble column with a draft tube. Chemical Engineering Science 49 (1), 139-144.

Lockett, M.J., Kirkpatrick, R.D., 1975. Ideal bubbly flow and actual flow in bubble columns. Transactions of the Institution of Chemical Engineers 53, 267-273.

Luo, H.P., Al-Dahhan, M.H., 2008. Local characteristics of hydrodynamics in draft tube airlift bioreactor. Chemical Engineering Science 63 (11), 3057-3068.

Mei, R., Klausner, J.F., Lawrence, C.J., 1994. A note on the history force on a spherical bubble at finite Reynolds number. Physics of Fluids 6, 418-420.

Merchuk, J.C., Ladwa, N., Cameron, M., 1994. Concentric-tube airlift reactors: effects of geometrical design on performance. AIChE Journal 40 (1105-1117).

Molerus, O., Kurtin, M., 1986. Hydrodynamics of bubble columns in the liquid circulation regime. Chemical Engineering Science 41 (10), 2685-2692.

Pironti, F.F., Medina, V.R., Calvo, R., Saez, A.E., 1995. Effect of draft tube position on the hydrodynamics of a draft tube slurry bubble column. Chemical Engineering Journal and the Biochemical Engineering Journal 60, 155-160.

Radl, S., Khinast, J.G., 2010. Multiphase flow and mixing in dilute bubble swarms. AIChE Journal 56, 2421.

Reza Mehmia, M., Towfighi, J., Bonakdarpour, B., Mehdi Akbarnejab, M., 2005. Gas hold-up and oxygen transfer in a draft-tube airlift bioreactor with petroleumbased liquids. Biochemical Engineering Journal 22 (2), 105-110.
Riboux, G., Risso, F., Legendre, D., 2010. Experimental characterization of the agitation generated by bubbles rising at high Reynolds number. Journal of Fluid Mechanics 643, 509-539.

Roghair, I., Lau, Y.M., Deen, N.G., Slagter, H.M., Baltussen, M.W., Van Sint Annaland, M., Kuipers, J.A.M., 2011. On the drag force of bubbles in bubble swarms at intermediate and high Reynolds numbers. Chemical Engineering Science 66 (14), 3204-3211.

Roig, V., Larue de Tournemine, A., 2007. Measurement of interstitial velocity of homogeneous bubbly flows at low to moderate void fraction. Journal of Fluid Mechanics 572, 87-110.

Rusche, H., Issa, R.I., 2000. The Effect of Voidage on the Drag Force on Particles, Droplets and Bubbles in Dispersed Two-Phase Flow. Technical Report BRITEEURAM III Program.

Schenk, O., Gärtner, K., 2004. Solving unsymmetric sparse systems of linear equations with PARDISO. Journal of Future Generation Computer Systems 20 (3), 475-487.

Shariati, F.P., Bonakdarpour, B., Reza Mehrnia, M., 2007. Hydrodynamics and oxygen transfer behaviour of water in diesel microemulsions in a draft tube airlift bioreactor. Chemical Engineering and Processing 46 (4), 334-342.

Talvy, S., Cockx, A., Liné, A., 2005. Global modelling of gas-liquid-solid airlift reactor. Chemical Engineering Science 60, 5991-6003.

Talvy, S., Cockx, A., Liné, A., 2007a. Modeling hydrodynamics of gas-liquid airlift reactor. AIChE Journal 53, 335-353.

Talvy, S., Cockx, A., Liné, A., 2007b. Modeling of oxygen mass transfer in a gas-liquid airlift reactor. AIChE Journal 53, 316-326.

Veera, U.P., Kataria, K.L., Joshi, J.B., 2001. Gas hold-up profiles in foaming liquids in bubble columns. Chemical Engineering Journal 84 (247-256).

Vejrazka, J., Vecer, M., Orvalho, S., Sechet, P., Ruzicka, M.C., Cartellier, A., 2010. Measurement accuracy of a mono-fiber optical probe in a bubbly flow. International Journal of Multiphase Flow 36 (7), 533-548.

Veldhuis, C., 2007. Leonardo's Paradox: Path and Shape Instabilities of Particles and Bubbles. Ph.D. Thesis, Twente University, Netherlands.

Vitankar, V.S., Joshi, J.B., 2002. A comprehensive one-dimensional model for prediction of flow pattern in bubble columns. Chemical Engineering Research and Design 80 (5), 499-512.

Wachi, S., Jones, A.G., Elson, T.P., 1991. Flow dynamics in a draft-tube bubble column using various liquids. Chemical Engineering Science 46 (2), 657-663.

Wallis, G.B., 1969. One Dimensional Two-phase Flow. Mcgraw Hill.

Winnikow, S., 1967. Letters to the editor. Chemical Engineering Science 22, 22-477.

Wongsuchoto, P., Pavasant, P., 2004. Internal liquid circulation in annulus sparged internal loop airlift contactors. Chemical Engineering Journal 100, 1-9.

Zenit, R., Koch, D.L., Sangani, A.S., 2001. Measurements of the average properties of a suspension of bubbles rising in a vertical channel. Journal of Fluid Mechanics 429, 307-342.

Zhang, N., Wang, T., Deng, Z., Wang, J., 2010. Self-oscillations in an airlift reactor. Chemical Engineering Journal 160 (1), 277-283. 